\title{
Zonas metropolitanas de México en 2000: conformación territorial y movilidad de la población ocupada
}

\author{
Jaime Sobrino*
}

En este documento se presenta una delimitación de las zonas metropolitanas de México en 2000, utilizando como criterios básicos el carácter urbano del municipio y los viajes intermunicipales por motivo de trabajo, y como criterios complementarios la dinámica demográfica y la importancia económica. Posteriormente se analizan los patrones de movimiento de la población ocupada entre la ciudad central y la periferia de cada zona metropolitana, construyendo una medida de centralidad para conocer el tipo de estructura ocupacional, y dos indicadores de nodalidad para identificar el patrón intrametropolitano de viajes por motivo de trabajo. El ejercicio de delimitación dio como resultado la existencia de 48 zonas metropolitanas, con una población conjunta de 47.3 millones de habitantes, que representan $48.6 \%$ de la nacional. En el interior de las zonas metro politanas predomina la residencia en la ciudad central, porque sólo 12 de las 48 zonas tienen una mayor proporción de su población en los municipios periféricos. Esta distribución poblacional propicia el predominio del patrón de viajes por motivo de trabajo de la periferia hacia la ciudad central. La movilidad laboral intrametropolitana se expli$c a$, en general, por la etapa de metropolitanismo que atraviesa cada metrópoli, en tanto que los flujos periferia-centro se relacionan también con una especialización del comercio en la estructura económica metropolitana, mientras que los desplazamientos centroperiferia ocurren con mayor frecuencia relativa en las zonas de mayor tamaño poblacional.

Palabras clave: regiones urbanas funcionales, etapas de metropolitanismo, movilidad intrametropolitana.

Fecha de recepción: 15 de octubre de 2002.

Fecha de aceptación: 24 de marzo de 2003.

\section{Introducción}

La conformación de una zona metropolitana ocurre cuando una ciudad, independientemente de su tamaño, rebasa su límite territorial político administrativo para conformar un área urbana ubicada en dos o más municipios; en otras palabras, la metropolización de una ciudad tiene lugar cuando, en su proceso de expansión, utiliza para el desarrollo urbano suelo que pertenece a uno o más municipios en los cuales no se ubica la ciudad central.

* Profesor-investigador del Centro de Estudios Demográficos y de Desarrollo Urbano de El Colegio de México. Correo electrónico: ljsobrin@colmex.mx 
La delimitación operativa de una zona metropolitana considera los siguientes elementos: $i$ ) componente demográfico, que tiene que ver con el crecimiento de la población y los movimientos intrametropolitanos centro-periferia; ii) mercado de trabajo, en cuanto a la estructura y dinámica de la economía local, ritmos de desconcentración del empleo y tendencias de relocalización espacial de cada sector económico; iii) conformación territorial, determinado por las características de la expansión urbana -continua, sectorial, axial o discontinua-, y iv) dimensión política, en función del grado de fragmentación del territorio en unidades político administrativas.

Las metrópolis son, generalmente, las áreas más dinámicas del cambio económico y demográfico en buena parte de los sistemas nacionales de ciudades, y la palabra metrópoli se ha utilizado rutinariamente como sinónimo de gran ciudad (Kasinitz, 1995). Según datos de las Naciones Unidas, en 1950 había en el planeta ocho metrópolis con población superior a cinco millones de personas y, en ese entonces, la concentración demográfica en grandes ciudades parecía ser asunto preferente del mundo desarrollado, porque sólo dos de ellas estaban en países en desarrollo (Shanghai y Buenos Aires); en 2000 se observa una multiplicación sustantiva, pues había ya 41 aglomeraciones con más de cinco millones de habitantes, y se transitaba hacia su mayor ubicación en los países en vías de desarrollo, pues 30 estaban principalmente en China, India, el sureste asiático y Latinoamérica (United Nations, 1999).

La multiplicación de las zonas metropolitanas durante la segunda mitad del siglo Xx ha sido marco recurrente para el estudio de nuevos patrones en los procesos nacionales de urbanización, lo cual ha propiciado que los sistemas de asentámientos se dividan, por un lado, entre urbanos y rurales, o la manifestación del tránsito de una economía agrícola a otra de carácter urbano, y, por otro, entre metropolitanos y no metropolitanos. En el dominio de lo metropolitano, los estudios se han abocado tanto al análisis de la interdependencia de la ciudad central y su periferia, como al seguimiento de la evolución intrametropolitana, o etapas de metropolitanismo, que describen los desplazamientos, primero de la población y posteriormente de las actividades económicas, desde la ciudad central hasta la periferia (véase Busquets, 1993; Suarez-Villa, 1988).

En México el fenómeno de metropolización se inició en la primera parte del siglo Xx, y para 1950 las ciudades centrales de México, Monterrey, Orizaba, Tampico y Torreón habían rebasado sus límites 
político administrativos; el Distrito Federal en el primer caso y sus municipios respectivos en las demás. La Ciudad de México sobresalió hasta 1960 porque alcanzó una de las mayores tasas de crecimiento poblacional y económico dentro del emergente sistema urbano nacional, y esto le permitió consolidar su papel jerárquico en dicho sistema. A partir de esa fecha otro conjunto de ciudades, aprovechando las fuerzas centrífugas para la desconcentración territorial, o los efectos centrípetos de la gran capital, propiciaron el inicio de una nueva fase en el ciclo del desarrollo urbano nacional, la de la polarización regresiva. Esta fase se vislumbró con mayor nitidez a partir de 1980, ya que desde entonces la tasa de crecimiento poblacional de la Ciudad de México ha sido menor que la del país en su conjunto. ${ }^{1}$

A pesar de la cierta madurez del fenómeno metropolitano en México, el gobierno federal no ha proporcionado criterios operativos para la delimitación de zonas metropolitanas, lo que ha impedido la existencia de información uniforme sobre ellas entre las instancias de gobierno. De manera complementaria, no se ha creado un marco normativo suficiente para promover la planeación territorial desde una perspectiva metropolitana, ni tampoco los instrumentos necesarios para la provisión de servicios públicos que manifiestan evidentes economías de escala en su prestación (vialidades, autopistas, agua potable, electricidad, tratamiento de aguas residuales, terminales de autotransporte, ferropuertos y aeropuertos). Además de estas razones que tienen que ver con la administración territorial, la utilidad de definir y delimitar las zonas metropolitanas consiste en contar con unidades de estudio adecuadas que faciliten una apreciación correcta de las dimensiones y características del proceso global de urbanización en el país, así como de la estructura y dinámica de este tipo de microrregiones urbanas funcionales.

En este documento se presenta una propuesta de delimitación de las zonas metropolitanas existentes en el país en el año 2000. A diferencia de otros ejercicios en donde la interrelación funcional se estima de manera indirecta, en éste se toma como eje de análisis la variable viajes intermunicipales por motivo de trabajo, lo que permite una estimación menos indirecta de la interrelación funcional. Esta adecuación se logra con la información disponible del Censo general de

${ }^{1}$ Para conocer los preceptos de la teoría de los ciclos del desarrollo urbano véase Combes, Dalla Longa y Raybould, 1989, y Geyer y Kontuly, 1993. 
población y vivienda de 2000 , en específico de los resultados de la muestra censal. Posteriormente se analizan las matrices origen-destino de viajes por motivo de trabajo para cada zona metropolitana, lo que permite identificar el tipo de estructura económica y el patrón intrametropolitano de viajes. Por último se determinan las variables explicativas del patrón de flujos.

\section{Zonas metropolitanas de México en 2000}

A lo largo del planeta, los criterios técnicos y operativos que se utilizan para la delimitación de las zonas metropolitanas están inspirados, en mayor o menor medida, en la experiencia estadunidense. En ese país el término metropolitano se empezó a utilizar hacia mediados del siglo XIX para referirse a las grandes ciudades de Nueva York, Filadelfia, Boston y Chicago (véase Weber, 1967: 20-40), en tanto que para el censo de 1950, un comité federal intergubernamental, dirigido por la Oficina de Presupuesto y con apoyo del personal de la Oficina de Censos, estableció los criterios operativos para delimitar las áreas metropolitanas (Rain, 1999: 769); se definieron áreas metropolitanas estándar (SMA por su sigla en inglés) porque las agencias federales representadas en el comité estuvieron de acuerdo en utilizar dichas unidades como entes normativos para la expresión del desarrollo urbano de la periferia de las ciudades centrales (U.S. Bureau of the Census, 1959).

Para los censos de 2000, los criterios operativos para la delimitación de áreas metropolitanas fueron los siguientes: 1) una ciudad central de 50000 o más habitantes, o dos ciudades contiguas que integran una misma comunidad con una población combinada de al menos 50000 habitantes y un mínimo de población de 15000 para la menor; 2) el resto del condado al que pertenece la ciudad central o los de las ciudades contiguas; 3) condados adyacentes que cumplan con: i) $75 \%$ o más de su población ocupada desempeñe actividades no agropecuarias; ii) al menos $15 \%$ de su población ocupada trabaje en la ciudad central, o al menos $25 \%$ de su demanda ocupacional resida en la ciudad central; iii) al menos $50 \%$ de là población del condado viva en núcleos con densidades de 150 personas por milla cuadrada (58 habitantes por kilómetro cuadrado); $i v$ ) oferta ocupacional no agropecuaria de al menos 10000 personas o al menos $10 \%$ de la de la ciudad central, y $v$ ) tasa de crecimiento poblacional (Pacione, 
2001: 23; Rain, 1999: 750). Esto significa que los criterios para la inclusión de condados adyacentes a un área metropolitana obedecen a dos elementos básicos: $i$ ) carácter urbano, en términos del porcentaje de su población económicamente activa (PEA) no agropecuaria, y ii) carácter de integración, referida a la comunicación económica y social entre la ciudad central y la periferia; integración medida en función de los viajes por motivo de trabajo.

El concepto y la delimitación operativa de las zonas metropolitanas en otros países del mundo han seguido, con mayor o menor intensidad, la experiencia estadunidense; sin embargo se deben destacar aportaciones como la del Reino Unido, en donde hacia principios del siglo XX se utilizó la palabra conurbación para referirse a ciudadesregiones o agregados urbanos de significativo tamaño como Londres y Manchester, así como el término ciudades millonarias, aparecido en 1935 para referirse a las seis grandes conurbaciones del país existentes en ese entonces, todas ellas con una población superior a un millón de habitantes. En el censo poblacional de 1950 aparecieron las primeras delimitaciones de las conurbaciones, conformadas por el agrupamiento de áreas de autoridad local (General Register Office, 1961).

A partir de 1961, y gracias a los trabajos del Grupo de Planeación Política y Económica, el censo de población británico proporciona información de dos agregados territoriales basados en la variable viajes por motivo de trabajo: 1) áreas metropolitanas laborales estándar (SMLA) , y 2) áreas metropolitanas económicas laborales (MELA). Si bien ambas conformaciones no tienen un estatus oficial, en cambio son los equivalentes a las SMA estadunidenses (Goodall, 1987: 301; Pacione, 2001: 23). Cada SMLA consiste en un centro laboral y un contorno metropolitano de áreas de autoridad local con elevada interrelación con el centro. El centro debe cubrir tres criterios: 1) la densidad de la demanda ocupacional en el área de autoridad local debe superar los 14 trabajadores por hectárea; 2) el total de la demanda ocupacional debe exceder 20000 trabajadores, y 3) las áreas de autoridad local que forman parte del centro deben estar físicamente contiguas. Por otro lado, las áreas de autoridad local del contorno metropolitano deben cumplir con: i) contigūidad física con el centro de la conurbación, y ii) más de $15 \%$ de su oferta ocupacional debe trabajar en el centro. Como criterio adicional, la SMLA debe tener una población conjunta de al menos 70000 habitantes. En términos de superficie, las SMLA son más reducidas que las MELA, puesto que estas últimas in- 
corporan no sólo un primer contorno de áreas de autoridad local, sino otro exterior que se caracteriza por un menor volumen relativo de viajes al centro por motivo de trabajo y que representa hasta $10 \%$ de su oferta ocupacional.

El fenómeno metropolitano en México fue reconocido oficialmente por el gobierno federal durante la década de los setenta, cuando el concepto de conurbación se integró al sistema nacional de planeación del desarrollo urbano. En el artículo 21 de la Ley General de Asentamientos Humanos de 1976 se establece que: "...el fenómeno de conurbación se presenta cuando dos o más centros urbanos situados en territorios municipales de dos o más entidades federativas forman una continuidad geográfica..." (H. Congreso de la Unión, 1976: 26). Posteriormente, el gobierno federal hizo explícita la diferenciación de conurbaciones al identificar las de corte interestatal con lo expuesto en el artículo 21 de la LGAH, las intraestatales a la unión de dos o más centros de población ubicados en municipios pertenecientes a una sola entidad federativa, y las internacionales cuando el fenómeno de conurbación ocurre en una franja binacional (Secretaría de Asentamientos Humanos y Obras Públicas, 1978: 2).

Hacia finales de la década de los setenta apareció el libro El desarollo urbano de México, y en él se ofrece un concepto de zona metropolitana que desde entonces ha sido adoptado en los estudios urbanoregionales del país para referirse a la conformación y evolución metropolitanas. Según éste,

la zona metropolitana se define, en términos generales, como la extensión territorial que incluye a la unidad político administrativa que contiene a la ciudad central, y a las unidades político administrativas contiguas a ésta que tienen características urbanas, tales como sitios de trabajo, o lugares de residencia de trabajadores dedicados a actividades no agrícolas, y que mantienen una interrelación socioeconómica directa, constante e intensa con la ciudad central, y viceversa (Unikel, Ruiz y Garza, 1978: 118).

Por la importancia que se le otorga a la interrelación funcional, las zonas metropolitanas son sinónimo de microrregiones urbanas funcionales o de sistemas urbanos cotidianos.

De esta manera una zona metropolitana abarca uno o más municipios donde se halla la ciudad central, además de municipios periféricos contiguos, de carácter urbano y con interrelaciones significati- 
vas con-la ciudad central; en los municipios periféricos se realizan diferentes tipos de actividades industriales y de servicios, y en algunos casos actividades agrícolas de subsistencia. Buen número de municipios periféricos son asiento de núcleos habitacionales con producción de viviendas por autoconstrucción, importantes movimientos hacia la ciudad central por motivo de trabajo, elevado crecimiento demográfico ocasionado en parte por la migración de corte intrametropolitano del municipio central hacia éstos, y problemas de tipo urbano y social que condicionan su organización y funcionamiento (Ziccardi, 2000: 16).

En México, sin lugar a dudas, los ejercicios metodológicos con mayor rigor técnico para la delimitación de zonas metropolitanas fueron elaborados por Unikel, Ruiz y Garza para las metrópolis existentes en 1970 (Unikel, Ruiz y Garza, 1978: 119-135) y por Negrete y Salazar para las zonas metropolitanas de 1980 (Negrete y Salazar, 1986); por medio de un ejercicio estadístico de componentes principales y análisis discriminatorio, determinaron la existencia de microrregiones urbanas con la máxima homogeneidad en su interior y la máxima heterogeneidad entre ellas y los municipios contiguos circundantes; las variables que utilizaron con tal propósito fueron: $i$ ) nivel de urbanización; ii) tasa de crecimiento demográfico; iii) elasticidad de crecimiento de la PEA no agropecuaria; $i v$ ) densidad de población; v) productividad industrial, y $v i$ ) distancia entre la ciudad central y las cabeceras de los municipios periféricos. ${ }^{2}$

Los resultados de ambos estudios han sido retomados en publicaciones del sector público, siendo un ejemplo el Consejo Nacional de Población (1994), en tanto que las delimitaciones dèl INEGI se han basado más en la unión física de dos o más localidades censales con una población de al menos 2500 habitantes (véase, por ejemplo, INEGI, 1991), mientras que los programas nacionales de desarrollo urbano 1995-2000 y 2001-2006 hacen referencia a las zonas metropolitanas, pero con la limitante de que no explican el procedimiento utilizado para su delimitación, como tampoco la conformación exacta de buen número de ellas (véase Poder Ejecutivo Federal, 1996: 73-84, y Poder Ejecutivo Federal, 2001: 58-61).

${ }^{2}$ Otras propuestas metodológicas relevantes para la delimitación de la Zona Metropolitana de la Ciudad de México aparecen en: Arias, 1990; Delgado, Anzaldo y Larralde, 1999; Gobierno del Distrito Federal, Secretaría de Desarrollo Social y Gobierno del Estado de México, 1998; Negrete, 2000; Rubalcava y Schteingart, 1985. 
El ejercicio para la propuesta de delimitación de zonas metropolitanas de México en 2000 que se presenta en este documento se basa en el uso de los siguientes criterios: $i$ ) carácter urbano del municipio; ii) interrelación funcional, y iii) dinámica demográfica. Las diferencias respecto al procedimiento de Unikel, Ruiz y Garza, y Negrete y Salazar son las siguientes:

En los primeros estudios el carácter urbano del municipio se evaluó en términos del porcentaje de su PEA ocupado en actividades no agropecuarias (al menos 66\%), del nivel de urbanización, o medida de concentración de la población municipal en localidades de 5000 y más habitantes, y de la densidad de pobiación municipal. En este caso el carácter urbano se atribuyó a todos aquellos municipios con una localidad censal de al menos 15000 habitantes en el año 2000, más aquellos en donde $50 \%$ o más de su población residía en localidades de 2500 a 14999 habitantes, y cuya PEA no agropecuaria era de al menos $75 \%$. La razón de considerar este segundo conjunto consiste en reconocer el hecho de la expansión metropolitana de manera discontinua, incluyendo localidades que fungen como colonias periféricas a la ciudad central.

Por lo que respecta al criterio de integración funcional, en los primeros estudios se midió indirectamente con el uso de dos variables: tasa de crecimiento poblacional, y distancia entre la ciudad central y la cabecera de los municipios perifẹricos. Con la información disponible del censo de población de 2000 , en específico los resultados del cuestionario muestral (INEGI, 2002), la interrelación ahora se puede medir de forma menos indirecta y utilizando la variable viajes intermunicipales por motivo de trabajo. Por último, la variable tasa de crecimiento municipal se utilizó aquí para ponderar el papel de los municipios periféricos en la consecución de las diversas etapas de metropolitanismo evidenciadas por la microrregión urbana funcional.

El proceso metodológico utilizado para la delimitación de las zonas metropolitanas se puede sintetizar en dos grandes actividades: $i$ ) identificación del municipio central, y ii) determinación de sus municipios periféricos. Para identificar los municipios centrales se seleccionaron aquellos con una localidad en el año 2000 de 50000 y más habitantes, resultando 177 municipios. Sin embargo varios de éstos son contiguos o continuos a una verdadera ciudad central (como los casos de Tlaquepaque, Tonalá y Zapopan, localidades de 50000 y más habitantes pero periféricas a la ciudad central de Guadalajara), por lo que el número de municipios centrales potenciales fue de 117 . 
El parámetro de 50000 habitantes para considerar a la ciudad central, si bien se hereda de la tradición estadunidense, es pertinente para México por los siguientes motivos: i) sólo seis municipios con este tipo de localidad tenían un grado de urbanización en 2000 inferior a 50\% (Allende, Dolores Hidalgo y Valle de Santiago, Guanajuato; Guasave, Sinaloa; Cárdenas, Tabasco, y San Andrés Tuxtla, Veracruz), siendo municipios con una superficie de más de $1000 \mathrm{~km}^{2} ; 3$ ii) sólo una localidad con ese tamaño tenía en el año 2000 menos de $75 \%$ de su PEA no agropecuaria (Tecomán), y iii) la eficiencia económica en 1998 de las ciudades entre 50000 y 99999 habitantes fue sólo $5 \%$ inferior respecto a la obtenida por las urbes de entre $100000 \mathrm{y}$ 249999 habitantes, pero $47 \%$ superior a la de las localidades de 15000 a 49999 habitantes. ${ }^{4}$

Se determinó que los municipios periféricos eran aquellos que estaban contiguos o continuos a algún municipio central y cumplían con los siguientes criterios:

- Carácter urbano: con una localidad de 15000 y más habitantes, o con un grado de urbanización de al menos $50 \%$ en municipios que no tenían una localidad de al menos 15000 habitantes (el grado de urbanización se obtuvo al dividir la población de las localidades de 2500 a 14999 habitantes y PEA no agropecuaria superior a $75 \%$ entre la población total municipal).

- Integración funcional: viajes por motivo de trabajo al municipio central y a los municipios integrantes de la zona metropolitana, que representaran al menos $15 \%$ de la PEA del municipio, o que $25 \%$ de la población ocupada en el municipio en cuestión residiera en el municipio central y en periféricos de la zona metropolitana.

- Dinámica demográfica: tasa de crecimiento poblacional del municipio periférico igual o mayor que la del municipio central, o que la del país en su conjunto, por lo menos en algún periodo intercensal entre 1950 y 2000.

- Importancia económica: valor bruto de la producción per cápita municipal en 1998 de las actividades industrial, comercial y de servi-

${ }^{3}$ Los 2443 municipios existentes en 2000 tenian una superficie promedio de 804 $\mathrm{km}^{2}$, una desviación estándar de $2102 \mathrm{~km}^{2}$, y un coeficiente de variación de 261 por ciento.

${ }^{4}$ La eficiencia económica se calculó dividiendo los ingresos derivados de las actividades industrial, comercial y de servicios, según la información municipal de los censos respectivos, entre la población de la ciudad o del área metropolitana estimada para 1998. 
cios de por lo menos 25000 pesos corrientes, monto equivalente al promedio nacional.

Con la información de la muestra censal se construyó, para cada una de las 117 potenciales zonas metropolitanas, una matriz origendestino de viajes municipales por motivo de trabajo de la siguiente forma (se ejemplifica una conformada con tres municipios):

FIGURA 1

Matriz origen-destino de viajes por motivo de trabajo

\begin{tabular}{cccccc}
\hline Origen-destino & $I$ & $j$ & $k$ & Resto & Total \\
\hline $\mathrm{I}$ & $\mathrm{V}_{\mathrm{ii}}$ & $\mathrm{V}_{\mathrm{ij}}$ & $\mathrm{V}_{\mathrm{ik}}$ & $\mathrm{V}_{\mathrm{ir}}$ & $\sum_{\mathrm{i} *}$ \\
$\mathrm{~J}$ & $\mathrm{~V}_{\mathrm{ji}}$ & $\mathrm{V}_{\mathrm{jj}}$ & $\mathrm{V}_{\mathrm{jk}}$ & $\mathrm{V}_{\mathrm{jr}}$ & $\sum_{\mathrm{j} *}$ \\
$\mathrm{~K}$ & $\mathrm{~V}_{\mathrm{ki}}$ & $\mathrm{V}_{\mathrm{kj}}$ & $\mathrm{V}_{\mathrm{kk}}$ & $\mathrm{V}_{\mathrm{kr}}$ & $\sum_{\mathrm{k}}$ \\
Total & $\sum_{* \mathrm{I}}$ & $\sum_{* \mathrm{j}}$ & $\sum_{*_{\mathrm{k}}}$ & $\sum_{* \mathrm{r}}$ & $\Sigma$ \\
\hline
\end{tabular}

en donde $V_{\text {ii }}$ es la PEA muestral que reside en el municipio i y trabaja en ese mismo municipio; $V_{\mathrm{ij}}$ es la PEA que vive en i y trabaja en $\mathrm{j}$, y $\mathrm{V}_{\mathrm{ir}}$ es la $P E A$ residente en el municipio i que declaró trabajar en otro municipio no integrante de la zona metropolitana, más aquellos que no especificaron el municipio en donde trabajan.

Para expandir la información muestral a los datos totales, por ejemplo igualar el monto de la muestra $\left(\sum_{\mathrm{i} *}\right)$ del municipio i con su PEA total, la información de la muestra indica el factor de ponderación para cada individuo; sin embargo, por la enorme complejidad que significaba el uso de dichos ponderadores para obtener la matriz final, se decidió utilizar el cociente de cada renglón (por ejemplo, $\mathrm{V}_{\mathrm{ii}}$ $/ \Sigma_{i *}$ ) y se multiplicó por su PEA registrada en el censo de población.

Aparentemente lo indicado para determinar los municipios periféricos era aplicar alguna herramienta estadística de agrupamiento (análisis de conglomerados, de componentes principales, factorial o discriminatorio) en función de los valores de los cuatro criterios antes mencionados; sin embargo, al no buscar microrregiones urbanas homogéneas, sino más bien microrregiones urbanas funcionales, se optó por emplear un método de conjuntos para los 374 municipios potencialmente periféricos, todos ellos cumpliendo con al menos uno de los cuatro criterios antes mencionados. 
El conjunto A se construyó con los municipios que satisfacen el criterio de carácter urbano, mientras que el conjunto $\mathrm{B}$ aglutinó a los municipios que cubren el criterio de integración funcional, y el conjunto $\mathrm{C}$ agrupó a los municipios con una significativa dinámica demográfica en algún periodo intercensal en el lapso 1950-2000. En la intersección de los conjuntos A, B y C se encontraron 194 municipios periféricos, delimitando 35 zonas metropolitanas.

De manera adicional, 20 municipios que no se encuentran en la intersección $\mathrm{A}, \mathrm{B}$ y $\mathrm{C}$ presentan importancia económica o un valor bruto de la producción per cápita de las actividades industrial, comercial y de servicios superior a 25000 pesos corrientes en 1998; estas 20 unidades político administrativas conforman el conjunto $\mathrm{D}$, y la unión de éste con la intersección de los conjuntos $\mathrm{A}, \mathrm{B}$ y $\mathrm{C}$ permitió definir 40 zonas metropolitanas, y en ellas, salvo en Cancún y Cozumel, el volumen total de viajes intermunicipales por motivo de trabajo es de al menos 2000 , cifra que se considera el mínimo a cumplir en las aglomeraciones de carácter metropolitano.

Una revisión ulterior del monto de viajes intermunicipales por motivo de trabajo en las restantes zonas metropolitanas potenciales mostró que en ocho casos se rebasaba el volumen de 2000 , de ahí que, por último, se optara por incluirlas en el listado total de metrópolis del país.

Así, el espectro metropolitano de México en el año 2000 asciende a 48 zonas metropolitanas, conformadas con 51 unidades político administrativas correspondientes a la ciudad central y 240 periféricas (véase el cuadro 1). ${ }^{5}$ Con un ejercicio cartográfico se verificó la contigüidad y continuidad en cada una de las metrópolis (véase el mapa 1).

Los cuatro criterios utilizados permitieron dividir el universo municipal de análisis en tres categorías (entre paréntesis aparece el número de unidades político administrativas de cada una):

- Municipios centrales (51), en donde se ubica la ciudad central.

- Municipios metropolitanos (240), contiguos al municipio central o continuos a la zona metropolitana.

- Municipios no metropolitanos (134), contiguos al municipio central o a los metropolitanos y que logran sólo una de estas combinaciones de criterios: $i$ ) carácter urbano e integración funcional, pero sin

${ }^{5}$ En la Ciudad de México se definieron como ciudad central las delegaciones Benito Juárez, Cuauhtémoc, Miguel Hidalgo y Venustiano Carranza. Por ello el número de municipios centrales es 51 , pero el total de zonas metropolitanas es 48 . 
CUADRO 1

Zonas metropolitanas de México, 2000

\begin{tabular}{|c|c|c|c|c|c|c|c|c|c|}
\hline \multirow{2}{*}{\multicolumn{2}{|c|}{ Nüm. Nombre }} & \multicolumn{3}{|c|}{ Población } & \multicolumn{2}{|c|}{ Población \% } & \multicolumn{3}{|c|}{ Municipio } \\
\hline & & Total & Central & Periferia & Central & Periferia & Total & Central & Periféricos \\
\hline & Total & 47337133 & 20136038 & 27201095 & 42.5 & 57.5 & 291 & 51 & 240 \\
\hline 1 & Ciudad de México & 18180183 & 1692179 & 16488004 & 9.3 & 90.7 & 63 & 4 & 59 \\
\hline 2 & Guadalajara & 3733895 & 1646319 & 2087576 & 44.1 & 55.9 & 10 & 1 & 9 \\
\hline 31 & Monterrey & 3302411 & 1110997 & 2191414 & 33.6 & 66.4 & 15 & 1 & 14 \\
\hline 41 & Puebla & 1837168 & 1346916 & 490252 & 73.3 & 26.7 & 20 & 1 & 19 \\
\hline 5 & Toluca & 1471146 & 666596 & 804550 & 45.3 & 54.7 & 14 & 1 & 13 \\
\hline & León & 1414196 & 1134842 & 279354 & 80.2 & 19.8 & 4 & 1 & 3 \\
\hline 7 & Tijuana & 1274240 & 1210820 & 63420 & 95.0 & 5.0 & 2 & 1 & 1 \\
\hline 8 & Torreón & 1007291 & 529512 & 477779 & 52.6 & 47.4 & 4 & 1 & 3 \\
\hline 9 & Mérida & 865461 & 705055 & 160406 & 81.5 & 18.5 & 9 & 1 & 8 \\
\hline 10 & San Luis Potosí & 850828 & 670532 & 180296 & 78.8 & 21.2 & 2 & 1 & 1 \\
\hline 11 & Querétaro & 836895 & 641386 & 195509 & 76.6 & 23.4 & 4 & 1 & 3 \\
\hline $12 x$ & Aguascalientes & 761878 & 643419 & 118459 & 84.5 & 15.5 & 4 & 1 & 3 \\
\hline 13 & Cuernavaca & 759554 & 338706 & 420848 & 44.6 & 55.4 & 6 & 1 & 5 \\
\hline $14 \mathrm{r} \cdot \mathrm{r} \cdot \mathrm{r}$ & Villahermosa & 669326 & 520308 & 149018 & 77.7 & 22.3 & 3 & $i$ & 2 \\
\hline 15 & Tampico & 655760 & 295442 & 360318 & 45.1 & 54.9 & 4 & 1 & 3 \\
\hline 16 & Saltillo & 637273 & 578046 & 59227 & 90.7 & 9.3 & 3 & $i$ & 2 \\
\hline 17 & Veracruz & 593181 & 457377 & 135804 & 77.1 & 22.9 & 2 & 1 & 1 \\
\hline 18 & Celaya & 578996 & 382958 & 196038 & 66.1 & 33.9 & 4 & 1 & 3 \\
\hline 19 & Xalapa & 541965 & 390590 & 151375 & 72.1 & 27.9 & 6 & 1 & 5 \\
\hline 201 & Reynosa & 524692 & 420463 & 104229 & 80.1 & 19.9 & 2 & 1 & 1 \\
\hline 21 & Tuxtla Gutiérrez & 523482 & 434143 & 89339 & 82.9 & 17.1 & 3 & 1 & 2 \\
\hline 22 & Oaxaca & 517683 & 256130 & 261553 & 49.5 & 50.5 . & 25 & 1 & 24 \\
\hline
\end{tabular}




\begin{tabular}{|c|c|c|c|c|c|c|c|c|}
\hline 23 Cancún & 431128 & 419815 & 11313 & 97.4 & 2.6 & 2 & 1 & 1 \\
\hline 24 Tepic & 342840 & 305176 & 37664 & 89.0 & 11.0 & 2 & 1 & 1 \\
\hline 25 Coatzacoalcos & 307724 & 267212 & 40512 & 86.8 & 13.2 & 3 & 1 & 2 \\
\hline 26 Monclova & 302899 & 193744 & 109155 & 64.0 & 36.0 & 4 & 1 & 3 \\
\hline 27 Pachuca & 287431 & 245208 & 42223 & 85.3 & 14.7 & 2 & 1 & 1 \\
\hline 28 Minatitlán & 285625 & 153001 & 132624 & 53.6 & 46.4 & 5 & 1 & 4 \\
\hline 29 Orizaba & 282093 & 118593 & 163500 & 42.0 & 58.0 & 8 & 1 & 7 \\
\hline 30 Tehuacán & 278577 & 226258 & 52319 & 81.2 & 18.8 & 5 & 1 & 4 \\
\hline 31 Tlaxcala & 267308 & 73230 & 194078 & 27.4 & 72.6 & 12 & 1 & 11 \\
\hline 32 Zacatecas & 246045 & 123899 & 122146 & 50.4 & 49.6 & 3 & 1 & 2 \\
\hline 33 Puerto Vallarta & 244536 & 184728 & 59808 & 75.5 & 24.5 & 2 & 1 & 1 \\
\hline 34 San Juan del Río & 229637 & 179668 & 49969 & 78.2 & 21.8 & 2 & 1 & 1 \\
\hline 35 Córdoba & 223341 & 177288 & 46053 & 79.4 & 20.6 & 2 & 1 & 1 \\
\hline 36 Cuautla & 222710 & 153329 & 69381 & 68.8 & 31.2 & 2 & 1 & 1 \\
\hline 37 Zamora & 216048 & 161918 & 54130 & 74.9 & 25.1 & 2 & 1 & 1 \\
\hline 38 Colima & 210766 & 129958 & 80808 & 61.7 & 38.3 & 2 & 1 & 1 \\
\hline 39 Poza Rica & 192027 & 152838 & 39189 & 79.6 & 20.4 & 2 & 1 & 1 \\
\hline 40 Guaymas & 180316 & 130329 & 49987 & 72.3 & 27.7 & 2 & 1 & 1 \\
\hline 41 Piedras Negras & 151149 & 128130 & 23019 & 84.8 & 15.2 & 2 & 1 & 1 \\
\hline 42 Tulancingo & 148528 & 122274 & 26254 & 82.3 & 17.7 & 2 & 1 & 1 \\
\hline 43 Apizaco & 137134 & 67675 & 69459 & 49.3 & 50.7 & 5 & 1 & 4 \\
\hline 44 Teziutlán & 133153 & 81156 & 51997 & 60.9 & 39.1 & 3 & 1 & 2 \\
\hline 45 Salina Cruz. & 129681 & 76452 & 53229 & 59.0 & 41.0 & 2 & 1 & 1 \\
\hline 46 Ocotlán & 125027 & 84200 & 40827 & 67.3 & 32.7 & 2 & 1 & 1 \\
\hline 47 Cozumel & 123843 & 60091 & 63752 & 48.5 & 51.5 & 2 & 1 & 1 \\
\hline 48 Moroleón & 100063 & 47132 & 52931 & 47.1 & 52.9 & 2 & 1 & 1 \\
\hline
\end{tabular}

Fuente: Cálculos elaborados con información de INEGI (2002), Información esladística, Sistema de consulla, Base de dalos de la muestra censal (cuestionario ampliado), Aguascalientes (página web); INEGI(2001), Principales resullados por localidad, Listados Unidos Mexicanos, XII Censo general de población y vivienda 2000, Aguascalientes (disco compacto). 


\section{MAPA 1}

\section{Zonas metropolitanas en 2000}

1. Ciudad de México

2. Guadalajara

3. Monterrey

4. Puebla

5. Toluca

6. León

7. Tijuana

8. Torreón

9. Mérida

10. San Luis Potosí

11. Querétaro

12. Aguascalientes

13. Cuernavaca

14. Villahermosa

15. Tampico

16. Saltillo

17. Veracruz

18. Celaya

19. Xalapa

20. Reynosa

21. Tuxula Gutiérrez

22. Oaxaca

23. Cancún

24. Tepic

25. Coatzacoalcos

26. Monclova

27. Pachuca

28. Minatitlán

29. Orizaba

30. Tehuacán

31. Tlaxcala

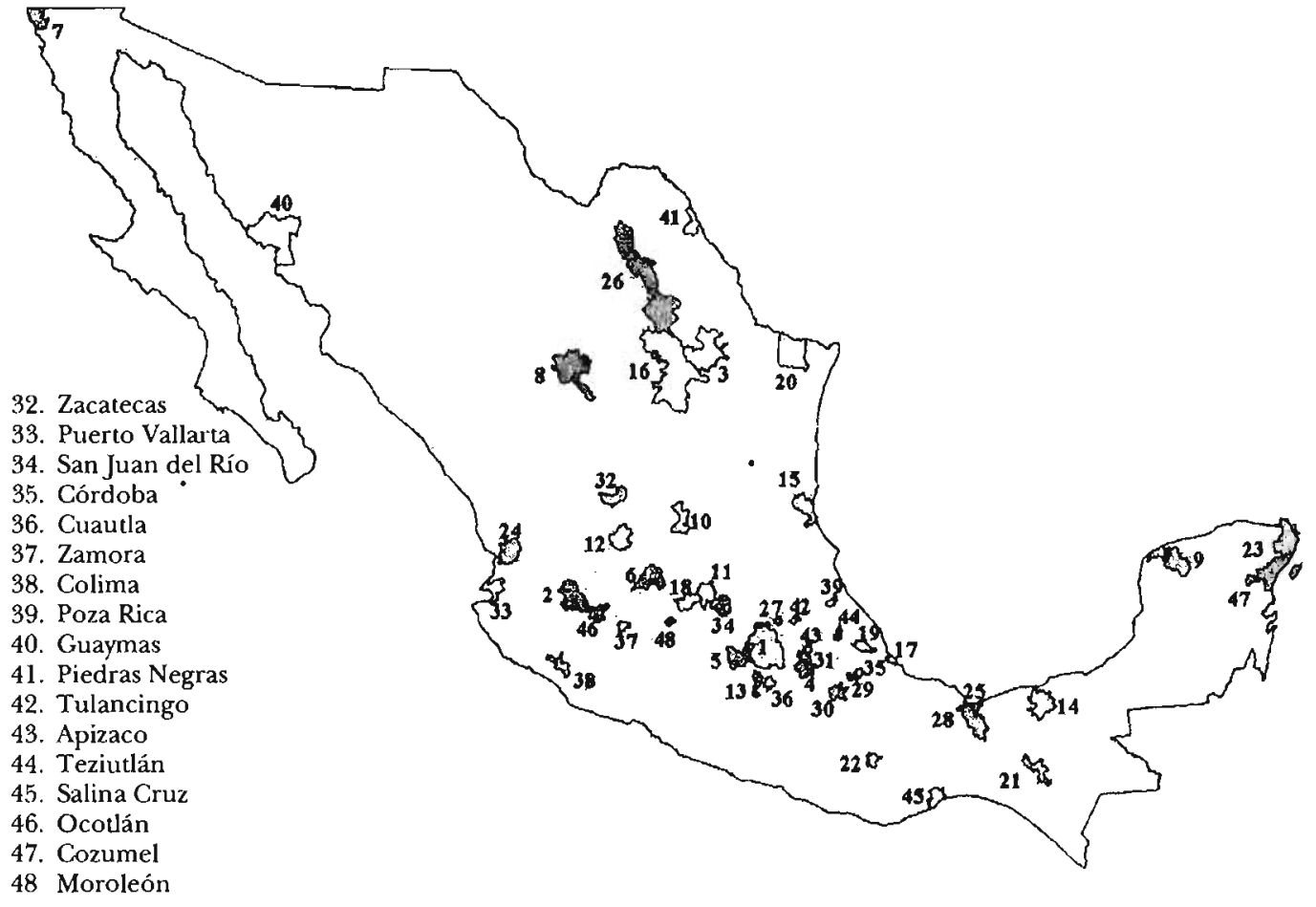


dinámica demográfica; ii) integración funcional y dinámica demográfica, pero sin carácter urbano; iii) carácter urbano, pero sin integración funcional y dinámica demográfica, y iv) integración funcional, pero con $0 \%$ de grado de urbanización y reducida dinámica demográfica.

En conjunto, las 48 zonas metropolitanas tuvieron en 2000 una población de 47.3 millones de habitantes, que representaba $48.6 \%$ de la nacional (véase el cuadro 1). Con esta delimitación se concluye que en el inicio del tercer milenio México cada vez se acerca más a ser un país fundamentalmente metropolitano, porque concentra más de la mitad de sus habitantes en este tipo de aglomeraciones.

De la población total metropolitana, 20.1 millones residían en los municipios centrales $(42.5 \%$ ) y 27.2 millones en los periféricos $(57.5 \%)$, lo que habla de un franco proceso de suburbanización. Sin embargo, si se eliminan los montos correspondientes a la Ciudad de México, los porcentajes se modifican a 63.2 y $36.7 \%$ respectivamente. De hecho, sólo las metrópolis de la Ciudad de México, Guadalajara, Monterrey, Toluca, Cuernavaca, Tampico, Oaxaca, Orizaba, Tlaxcala, Apizaco, Cozumel y Moroleón presentan un mayor monto poblacional en sus municipios periféricos en relación con el central (véase el cuadro 1).

La Ciudad de México es la principal zona metropolitana del país, tanto por su volumen de población como por su concentración económica y número de municipios metropolitanos. Su extensión abarca las 16 delegaciones del Distrito Federal, 45 municipios del Estado de México y dos de Hidalgo. En términos demográficos le siguen Guadalajara y Monterrey con más de tres millones de habitantes, y Puebla, Toluca, León, Tijuana y Torreón, todas ellas con más de un millón; por otro lado, Moroleón es la de menor tamaño de población y todo parece indicar que 100000 habitantes es el límite inferior que deben vencer las aglomeraciones urbanas del país para conformar un espectro territorial de carácter metropolitano.

Desde el punto de vista del número de municipios metropolitanos, a la Ciudad de México le siguen Oaxaca con 25, Puebla con 20, Monterrey con 15, Toluca con 14 y Tlaxcala con 12; estas seis metrópolis concentran $51.2 \%$ del total de municipios metropolitanos de todo el país.

En el cuadro A1 del anexo se presenta la conformación de cada zona metropolitana, su población en el año 2000 y los valores de los criterios de los municipios.

Cabe destacar en los municipios no metropolitanos la situación de Mérida y en menor medida la de Oaxaca, Puebla y Xalapa, capitales es- 
tatales que operan como nodos de carácter regional en cuanto a demanda ocupacional de buena parte de su población circundante que vive en municipios con características rurales. Estas capitales, junto con Tehuacán y Apizaco, ilustran con mayor nitidez el proceso de rurbanización, entendido ya no como la oposición entre el campo y la ciudad, ni la vinculación de lo rural con el uso de la tierra para labores agropecuarias, sino más bien como una ampliación de la interacción entre el campo y la ciudad mediante: $i$ ) la diversificación ocupacional; ii) la permanencia de la tenencia de la tierra; iii) las actividades agropecuarias relegadas a un segundo término; $i v$ ) la demanda de servicios urbanos, y v) la expansión urbana en suelo rural (véase Cruz, 2002).

La evolución demográfica de las zonas metropolitanas no es una tarea sencilla porque con el paso del tiempo se van conformando nuevas aglomeraciones de corte metropolitano, al tiempo que éstas van abarcando un mayor número de municipios. Una solución a dicho reto consiste en investigar posibles definiciones y revisar la pertinencia de los resultados. De esta manera, se proponen dos métodos alternativos para el estudio demográfico de las zonas metropolitanas de México en el periodo 1950-2000: i) delimitación móvil, reconociendo la creación de nuevas zonas metropolitanas y la anexión de nuevos municipios en ellas a través del tiempo, y ii) delimitación fija, utilizando un límite geográfico fijo para cada zona metropolitana, por ejemplo la delimitación aquí propuesta para 2000.

En el primer método se incorporan todos los cambios periódicos en la delimitación geográfica de las zonas metropolitanas, de tal manera que ni el número de zonas ni los municipios que las conforman son los mismos en el tiempo; este método permite analizar el cambio en la dimensión metropolitana del desarrollo urbano y la participación de ellas en los grados de concentración territorial de la población y las actividades económicas. Por su parte, en el método de delimitación fija el universo de análisis es el mismo para toda la serie de tiempo y tiene la ventaja de facilitar el acopio y procesamiento de información, asimismo no es afectado por la creación de nuevos municipios; con este procedimien to se puede estudiar con mayor detalle el ritmo de crecimiento económico y demogräfico de las aglomeraciones metropolitanas. ${ }^{6}$

${ }^{6}$ La idea de utilizar estos métodos se extrajo de Ehrlich y Gyourko, 2000, quienes los adecuaron para analizar los cambios en la participación demográfica de las metrópolis de Estados Unidos durante el siglo $\mathrm{xx}$. 
Con base en el método de delimitación móvil se puede apreciar que el número de zonas metropolitanas en el país ha ido aumentando de manera sistemática: en 1950 había tan sólo cinco (Ciudad de México, Monterrey, Torreón, Tampico y Orizaba), las cuales se conformaban con 22 unidades político administrativas y concentraban $14.8 \%$ de la población nacional. Por otro lado, en 2000 las aglomeraciones metropolitanas llegaron a 48 , conformadas con 291 municipios (incluyendo las 16 delegaciones del Distrito Federal) y su concentración demográfica alcanzó $48.6 \%$ (véase el cuadro 2). La tendencia ascendente de la participación de la población metropolitana respecto a la total del país induce a pensar que durante la primera década del siglo Xxi México se convertirá en un país preferentemente metropolitano porque más de la mitad de sus habitantes residirán en este tipo de microrregiones urbanas funcionales.

La mayor conformación absoluta de nuevas zonas metropolitanas ocurrió en la década de los setenta, con un incremento de 13 nuevas conurbaciones, seguida por los ochenta con 12 (véase el cuadro 2).

\section{CUADRO 2}

Población de las zonas metropolitanas, 1950-2000

\begin{tabular}{|c|c|c|c|c|c|c|}
\hline Concepto & 1950 & 1960 & 1970 & 1980 & 1990 & 2000 \\
\hline \multicolumn{7}{|l|}{ Población } \\
\hline $\begin{array}{l}\text { Tasa de } \\
\text { crecimiento }\end{array}$ & & 3.17 & 3.40 & 3.20 & 2.02 & 1.85 \\
\hline \multicolumn{7}{|c|}{ Delimitación mónil de zonas metropolitanas } \\
\hline Zonas & 5 & 7 & 18 & 31 & 43 & 48 \\
\hline Municipios & 22 & 34 & 73 & 143 & 209 & 291 \\
\hline Población & $\begin{array}{r}3782257 \\
148\end{array}$ & 7339111 & 14757101 & 26196591 & $\begin{array}{r}35183067 \\
433\end{array}$ & $\begin{array}{r}47337133 \\
48.6\end{array}$ \\
\hline \multicolumn{7}{|c|}{ Delimitación fija de zonas metropolitanas } \\
\hline Zonas & 48 & 48 & 48 & 48 & 48 & 48 \\
\hline Municipios & 271 & 273 & 276 & 278 & 280 & 291 \\
\hline $\begin{array}{l}\text { Población } \\
\text { total } \\
\text { Tasa de }\end{array}$ & 8143323 & 12755713 & 20187792 & 31001724 & 37830284 & 47337133 \\
\hline crecimiento & & 4.59 & 4.88 & 4.23 & 2.06 & 2.28 \\
\hline
\end{tabular}

Fuente: Cálculos elaborados con información de los censos generales de población y vivienda de 1950 a 2000. 
Durante los setenta, cinco de las 13 nuevas zonas se constituyeron en la Región Centro del país (Querétaro, Tlaxcala, Cuautla, Tulancingo y Apizaco), lo que de alguna manera esboza la emergencia de la ocurrencia de fuerzas centrípetas de la Ciudad de México hacia dicha región en el patrón de distribución territorial de la población y las actividades económicas, en tanto que dos se conformaron gracias al auge de la actividad petrolera (Coatzacoalcos y Minatitlán) y dos más por cierta dispersión de la actividad industrial a lo largo del territorio nacional (Celaya y Reynosa).

Por su parte, en los ochenta, y en el marco de la crisis de las finanzas públicas, el agotamiento del modelo de sustitución de importaciones y la nueva estrategia de desarrollo hacia la apertura comercial, la conformación de metrópolis en la Región Centro prosiguió (Pachuca, Tehuacán, San Juan del Río y Teziutlán), mientras que en el resto del territorio nacional surgieron otras de pequeño tamaño (Salina Cruz y Moroleón) y tres determinadas por su significativo crecimiento económico (León, Aguascalientes y Cancún).

Cabe mencionar que en los noventa se frenó considerablemente la creación de zonas metropolitanas al conformarse sólo cinco nuevas conurbaciones (Tijuana, Saltillo, Puerto Vallarta, Ocotlán y Cozumel).

Pero si bien en los noventa se contuvo la tendencia de conformación de nuevas metrópolis, en cambio este periodo se caracterizó por registrar el mayor incremento absoluto en el número de municipios metropolitanos, los cuales cambiaron de 209 en 1990 a 291 en 2000 , con un incremento de 82 , de los cuales más de la mitad los congregaron la Ciudad de México (16), Oaxaca (9), Tlaxcala (7), Monterrey (6) y Puebla (6). De esta manera, el número promedio de municipios por zona metropolitana aumentó de 4.4 en 1950 a 6.1 en 2000.

El mantener fija la delimitación de cada zona metropolitana permite apreciar con mayor claridad la dinámica de crecimiento de la población en este tipo de aglomeraciones. Por principio de cuentas se debe destacar que algunos municipios catalogados como metropolitanos en 2000 cedieron entre 1950 y 2000 parte de su territorio para la erección de 20 nuevas unidades político administrativas, situación más evidente en el estado de Tlaxcala, donde durante la década de los noventa se crearon 11 nuevas municipalidades con territorio de municipios pertenecientes a las metrópolis de Puebla, Tlaxcala y Apizaco.

La tasa de crecimiento de la población metropolitana fue significativamente superior a la de la población total del país en el lapso 1950-1980, pero en los ochenta fue similar y en los noventa registró 
un ligero repunte (véase el cuadro 2). Dicha situación se explica, sobre todo, por el comportamiento poblacional de la Ciudad de México, cuya tasa de crecimiento fue ampliamente mayor que la total nacional y la del resto de las zonas metropolitanas hasta 1980, en tanto que para $1980-1990$ se redujo a $0.8 \%$, y subió a $1.7 \%$ en los noventa. La evolución demográfica de la Ciudad de México ha permitido establecer dos grandes fases en el ciclo del desarrollo urbano nacional a lo largo del siglo XX: $i$ ) de concentración o primacía, de 1900 a 1960 , en donde la tasa de crecimiento de dicha metrópoli fue superior a la total y a la urbana del país; y ii) de polarización regresiva, desde 1960 y caracterizada por su menor ritmo de crecimiento demográfico respecto al resto del sistema urbano nacional (1960-1980) y del país en su conjunto (1980 a la fecha).

Por su parte, la tasa de crecimiento global de las 47 zonas metropolitanas restantes fue recurrentemente mayor que la del país en su conjunto en toda la serie de tiempo en estudio, y su valor en cada década fue alrededor de un punto porcentual por arriba de la del país, evidenciando con ello una permanencia en sus patrones migratorios y una atracción moderada de inmigrantes.

Al observar la tasa de crecimiento intercensal para cada zona metropolitana en el periodo 1950-2000 se advierte lo siguiente: i) Guadalajara fue la única de las siete metrópolis existentes en 1960 que obtuvo un ritmo de crecimiento de más de dos veces respecto al del país en su conjunto; ii) ninguna de las 18 metrópolis de 1970 alcanzó una tasa de crecimiento de hasta dos veces la nacional en el lapso 19601970; iii) Tuxtla Gutiérrez registró más del doble de la tasa nacional en los setenta, ochenta y noventa, en tanto que Cancún lo logró en los ochenta y noventa; iv) en los ochenta apareció el mayor número de zonas metropolitanas con un dinamismo dos o más veces más alto respecto al país en su conjunto, al anexarse a Tuxtla Gutiérrez y Cancún las conurbaciones de Salina Cruz, Villahermosa, Oaxaca, Monclova, Querétaro y San Juan del Río, y $v$ ) en los noventa, de las 48 zonas metropolitanas, cinco lograron una tasa dos veces más alta respecto a la del país: Cozumel, Cancún, Tijuana, Puerto Vallarta y Tuxtla Gutiérrez. Con esto se concluye el significativo ritmo de crecimiento demográfico de tres puertos turísticos en más de un periodo intercensal (Cancún, Puerto Vallarta y Cozumel), en tanto que las metrópolis con una vocación industrial lograron elevadas tasas de crecimiento en un solo lapso intercensal, y todas ellas en los ochenta (Querétaro, Monclova y San Juan del Río). 
Es importante mencionar por último que salvo Querétaro y San Juan del Río, ninguna otra metrópoli de la Región Centro del país logró una tasa de crecimiento dos veces más alta que la del país en su conjunto, por lo que los efectos difusores de la Ciudad de México no tuvieron un destino preferencial hacia alguna microrregión urbana funcional de tal región, sino más bien disperso.

\section{Movilidad intrametropolitana de la fuerza de trabajo}

Los estudios urbanos, conforme a una perspectiva de geografía económica, se han abocado al análisis de las zonas urbanas como puntos en el territorio, y han destacado las interrelaciones que ocurren entre ellas, o como áreas identificando los patrones de organización de la población y actividades económicas. Conforme a la segunda perspectiva se han ofrecido vertientes teóricas para la interpretación de la estructura interna de la ciudad y se han destacado los modelos concéntrico, sectorial, axial y policéntrico, comúnmente utilizados durante la primera mitad del siglo XX (Johnson, 1977: 170-195). La vertiginosa difusión de la mancha urbana en numerosas urbes del planeta propició la aparición de nuevas vertientes teóricas, tales como los modelos relacionados con la planeación del transporte (Hamburg y Sharkey, 1961), los focalizados en la transformación de suelo rural a habitacional (Stuart, 1965), el de metrópolis desarrollado por Ira Lowry (Massey y Cordey-Hayes, 1971), el de patrón de movimientos entre la ciudad central y su periferia (Berry y Kim, 1993; Erickson, 1983; Van der Laan, 1998).

El modelo clásico de ciudad monocéntrica representa una adecuación a la connotación intraurbana de los postulados del modelo de Von Thünen sobre la distribución de usos del suelo agropecuarios en las inmediaciones de un lugar de consumo. Sin embargo, para modelar la conformación contemporánea de la estructura metropolitana policéntrica es necesario replantear las nociones sobre los factores que determinan la selección residencial, la localización de las actividades económicas y la movilidad de la población ocupada en una vertiente intraurbana; esto significa abandonar la caja negra que encierra el concepto de economías externas y asumir que éstas ya no se aplican por igual a todos los productores dentro de la ciudad central y no a todos los productores fuera de aquel distrito (Fujita, Krugman y Venables, 2000: 15-24). 
En el análisis de la conformación metropolitana se han destacado dos variables: por un lado el nivel de metropolitanismo, que se asocia con la distribución intrametropolitana de la población en un momento determinado y que indica que a mayor participación de la población residente en la periferia, mayor nivel de metropolitanismo de la zona; este rango está en función de una serie de factores entre los que figuran el tamaño de la ciudad central, el número de municipios metropolitanos, la superficie de los municipios central y periféricos, y la densidad de población en el municipio central (Unikel, Ruiz y Garza, 1978: 145). La segunda variable se refiere a las etapas de metropolitanismo o proceso de cambio en la distribución de la población y de las actividades económicas, y que de manera general se caracteriza por un desplazamiento, primero de la población y posteriormente de las actividades económicas, del centro hacia la periferia.

En ambas variables se privilegia tanto el estudio de la distribución de la población y las actividades económicas como la naturaleza de los mercados territoriales de trabajo; por ello la movilidad de la fuerza de trabajo es una de las variables fundamentales para la delimitación de los sistemas urbanos cotidianos, o microrregiones urbanas funcionales. Dos elementos que se desprenden de la información de los viajes intermunicipales por motivo de trabajo consisten, por un lado, en el establecimiento de una tipología de las zonas metropolitanas en función del número de lugares centrales que contienen, y por otro lado, los patrones de movilidad de la población ocupada en el interior de cada zona metropolitana y los factores que explican dichos movimientos. Estos dos aspectos serán analizados a continuación.

Según los principios de la teoría del lugar central, una medida de centralidad se obtiene, en este caso, al comparar el número de personas que trabajan en una unidad territorial con el de los trabajadores que residen en dicha unidad, es decir, el cociente entre la demanda ocupacional (población ocupada) y la oferta ocupacional (PEA). Las unidades cuyo cociente es mayor que uno se consideran lugares centrales. La posición de un lugar central ya no se explica por su posición geográfica, sino más bien por su papel dentro del sistema de flujos intrametropolitanos (Van der Laan, 1998). Al aplicar la idea anterior, las zonas metropolitanas del país se dividen en cuatro tipos: 1) monocéntrica, cuando sólo en el municipio central el volumen de trabajadores ocupados es mayor que el de sus trabajadores residentes; 2) bifuncional, cuando esta situación se presenta tanto en el municipio central como en algún otro periférico; 3) policéntrica, cuando los luga- 
res centrales de una zona metropolitana son tres o más, y 4) de mercados de trabajo competitivos, cuando un porcentaje significativo de la PEA en los municipios periféricos trabaja en su misma unidad territorial, al tiempo que el volumen de la PEA residente del municipio central es mayor que el de su población ocupada.

En términos generales las zonas metropolitanas de México son predominantemente del tipo monocéntrico, porque 30 de las 48 caben en esa categoría, y son fundamentalmente las de menor tamaño poblacional que están integradas por un municipio central y uno periférico; la estructura ocupacional predominante en la zona metropolitana es de comercio con 12 casos, la industrial queda en segundo lugar con 10 y la de servicios en tercera posición con ocho. La tipología monocéntrica-servicios aglutina capitales estatales, centros turísticos y antiguos nodos industriales ahora en decadencia; la monocéntricaindustrial contiene metrópolis medianas cuya base económica se sostiene por la concentración de empresas maquiladoras o de gran tamaño; la monocéntrica-comercial está compuesta por una mezcla de zonas de menor tamaño y capitales estatales que fungen como centros regionales de comercialización (véase el cuadro 3). ${ }^{7}$

En la tipología bifuncional se ubican seis metrópolis cuya conformación metropolitana oscila entre cuatro y nueve municipios. De elias, cinco contienen una estructura ocupacional con especialización en la industria, lo que habla de la dispersión territorial relativa que manifiesta dicha actividad económica. Las zonas metropolitanas policéntricas son seis, y sin duda constituyen las aglomeraciones urbanas más complejas dentro del sistema urbano nacional; se caracterizan por ser, en términos generales, las de mayor tamaño demográfico y mayor cantidad de municipios periféricos involucrados. La actividad predominante es nuevamente la industrial con cuatro casos.

Por último, las zonas metropolitanas con mercados de trabajo competitivos suman seis y es un hecho que vale la pena profundizar en su estudio para ver si efectivamente se pueden considerar unidades territoriales de índole metropolitana. En todas ellas el porcentaje de viajes por motivo de trabajo de la PEA de los municipios periféricos hacia el central es a lo más $10 \%$, en tanto que éntre 10 y $50 \%$ de la demanda ocupacional de los municipios periféricos con estructura especializada en la in-

${ }^{7}$ La estructura ocupacional predominante se obtuvo con la aplicación de un índice de especialización local. 
CUADRO 3

Tipología de las zonas metropolitanas según estructura ocupacional

\begin{tabular}{|c|c|c|c|c|c|}
\hline \multirow{2}{*}{$\begin{array}{l}\text { Estructura } \\
\text { ocupacional }\end{array}$} & \multicolumn{5}{|c|}{ Tipologia } \\
\hline & \multicolumn{2}{|c|}{ Monocéntrica } & Bifuncional & Policéntrica & Competitiva \\
\hline \multirow{5}{*}{ Industria } & San Luis Potosí & Tehuacän & Guadalajara & Monterrey & León \\
\hline & Querétaro & San Juan del Río & Torreón & Puebla & Tijuana \\
\hline & Celaya & Piedras Negras & Aguascalientes & Toluca & Saltillo \\
\hline & Reynosa & Teziutlán & Monclova & Tlaxcala & Guaymas \\
\hline & Orizaba & Ocotlán & Apizaco & & \\
\hline \multirow{6}{*}{ Comercio } & Villahermosa & Cuautla & & Oaxaca & \\
\hline & Tuxtla Gutiérrez & Zamora & & & \\
\hline & Tepic & Poza Rica & & & \\
\hline & Pachuca & Tulancingo & & & \\
\hline & Minatitlán & Salina Cruz & & & \\
\hline & Córdoba & Moroleón & & & \\
\hline \multirow{5}{*}{ Servicios } & Mérida & Zacatecas & Tampico & Ciudad de México & Cancún \\
\hline & Cuernavaca & Puerto Vallarta & & & Cozumel \\
\hline & Veracruz & Colima & & & \\
\hline & Xalapa & & & & \\
\hline & Coatzacoalcos & & & & \\
\hline
\end{tabular}

Fuente: Cálculos elaborados con información de los censos industrial, comercial y de servicios de 1999, y de la muestra del Censo de población y vivienda de 2000 . 
dustria residen en la ciudad central, y menos de $5 \%$ en las zonas especializadas en servicios. Dichas zonas metropolitanas se delimitaron atendiendo básicamente a un criterio de contigüidad entre unidades político administrativas con estructura ocupacional similar y eficiencia económica superior al promedio nacional. Si se toma en cuenta el criterio de interrelación funcional, entonces Saltillo aprueba el examen para ser considerado zona metropolitana, pero no así León, Tijuana, Guaymas, Cancún y Cozumel. Allí faltaría realizar un estudio más a fondo y con alguna otra variable que cuantificara la interacción.

La tipología monocéntrica implica movimientos cotidianos por motivo de trabajo del arquetipo periferia-centro, mientras que la de mercados competitivos se convierte en su antítesis al mostrar un mayor volumen de movimientos del centro hacia la periferia; en la tipología bifuncional y policéntrica, los viajes por motivo de trabajo se escenifican desde municipios preferentemente habitacionales hasta otros convertidos en nodos de concentración económica, y hay un predominio hacia la ciudad central en términos de volumen.

Para comprobar lo anterior, los viajes intrametropolitanos por motivo de trabajo de cada zona se conjugaron según la figura 2 y se calcularon dos medidas de nodalidad.

El flujo cuyo origen son los municipios periféricos y su destino es el central contiene la movilidad tradicional intrametropolitana de la población ocupada y refleja el grado en el cual los trabajadores que viven en los suburbios se desplazan a la ciudad central para desempeñar sus actividades económicas; esto último se conoce como Nodalidad 1 (N1). ${ }^{8}$ Un valor alto de $\mathrm{N} 1$ indica que la mayoría de los trabaja-

FIGURA 2

Movilidad intrametropolitana de la población ocupada

\begin{tabular}{ccc}
\hline Origen-destino & Municipio central & Municipios periféricos \\
\hline $\begin{array}{c}\text { Municipios periféricos } \\
\text { (Nodalidad 1) }\end{array}$ & $\begin{array}{c}\text { Movilidad tradicional } \\
\text { (1- Nodalidad 1) }\end{array}$ & Desplazamientos cortos \\
$\begin{array}{c}\text { Municipio central } \\
\text { (1- Nodalidad 2) }\end{array}$ & $\begin{array}{c}\text { Empleados locales } \\
\text { (Nodalidad 2) }\end{array}$ & Movilidad reversible \\
\hline
\end{tabular}

Fuente: Van der Laan (1998), "Changing Urban Systems: An Empirical Analysis at Two Spatial Levels", Regional Studies, vol. 32, núm. 3, p. 239.

${ }^{8} \mathrm{La} N 1$ se obtuvo de la siguiente forma: $\mathrm{Nl}=\left(\mathrm{V}_{\mathrm{ji}}+\mathrm{V}_{\mathrm{kl}}\right) /\left(\left(\Sigma_{\mathrm{j}^{*}}-\mathrm{V}_{\mathrm{ir}}\right)+\left(\Sigma_{\mathrm{k}}-\mathrm{V}_{\mathrm{kr}}\right)\right)$, según nomenclatura de la figura 1 y suponiendo que el municipio i representa al central. 
dores que viven en la periferia se desplazan a la ciudad central y simultáneamente muestra un bajo nivel de desplazamientos de corta distancia. En contraste, un bajo valor de Nl supone un sistema urbano cotidiano más disperso, en donde la demanda ocupacional no sólo se concentra en la ciudad central sino también en algunos nodos de actividad desarrollados en la periferia.

Por otro lado, es importante considerar la movilidad reversible, o Nodalidad 2 (N2), en la cual se mide el grado en el cual los residentes de la ciudad central se desplazan a la periferia para realizar sus actividades productivas. ${ }^{9} \mathrm{Si}$ N2 es alto, entonces la periferia ha desarrollado nodos de concentración de actividades económicas que ocupan a una cantidad considerable de residentes de la ciudad central; como corolario, si también (1-N1) es alto se está ante una estructura metropolitana descentralizada.

Para determinar el patrón funcional de la movilidad en las zonas metropolitanas de México, los valores de N2 y N1 se expresaron en una gráfica, la cual se divide en cuatro cuadrantes (véase la gráfica 1): cuadrante I, en donde $\mathrm{N} 1$ es alto y $\mathrm{N} 2$ bajo, lo que denota un patrón altamente centralizado, cuadrante II, con $\mathrm{N} 1$ alto y N2 alto, que indica una reciprocidad de movimientos y que ocurre, por ejemplo, cuando en los suburbios se demanda fuerza de trabajo con alta especialización, pero los residentes con tal especialización residen preferentemente en la ciudad central, lo que implica una cierta discordancia en la organización territorial del mercado de trabajo; cuadrante III, N1 bajo y N2 alto, lo cual muestra una complementariedad de movimientos y la tendencia hacia un patrón descentralizado; cuadrante IV, con N1 bajo y N2 bajo, determinando un dualismo en la conformación territorial de los mercados de trabajo.

Para las 48 zonas metropolitanas, la gráfica muestra el predominio del patrón centralizado de viajes por motivo de trabajo (cuadrante I), ya que hay 26 conurbaciones en tal situación, de las cuales 23 contienen una estructura monocéntrica, dos una policéntrica-Puebla y Oaxaca- y Aguascalientes una estructura bifuncional. Los municipios periféricos que tienen una medida de centralidad mayor que uno en estas tres metrópolis contienen parques o zonas industriales, pero el flujo total hacia éstos es poco representativo respecto al que va hacia el municipio central. Por su parte, en el cuadrante II (reciprocidad) aparecen nueve zonas que tienen fundamentalmente una

${ }^{9} \mathrm{~L}$ a N2 se obtuvo así: $\mathrm{N} 2=\left(\mathrm{V}_{\mathrm{ij}}+\mathrm{V}_{\mathrm{ik}}\right) /\left(\Sigma_{\mathrm{i} *}-\mathrm{V}_{\mathrm{ir}}\right)$, según nomenclatura de la figura 1. 
GRÁFICA 1

Patrones de movilidad intrametropolitana por tipo de estructura ocupacional

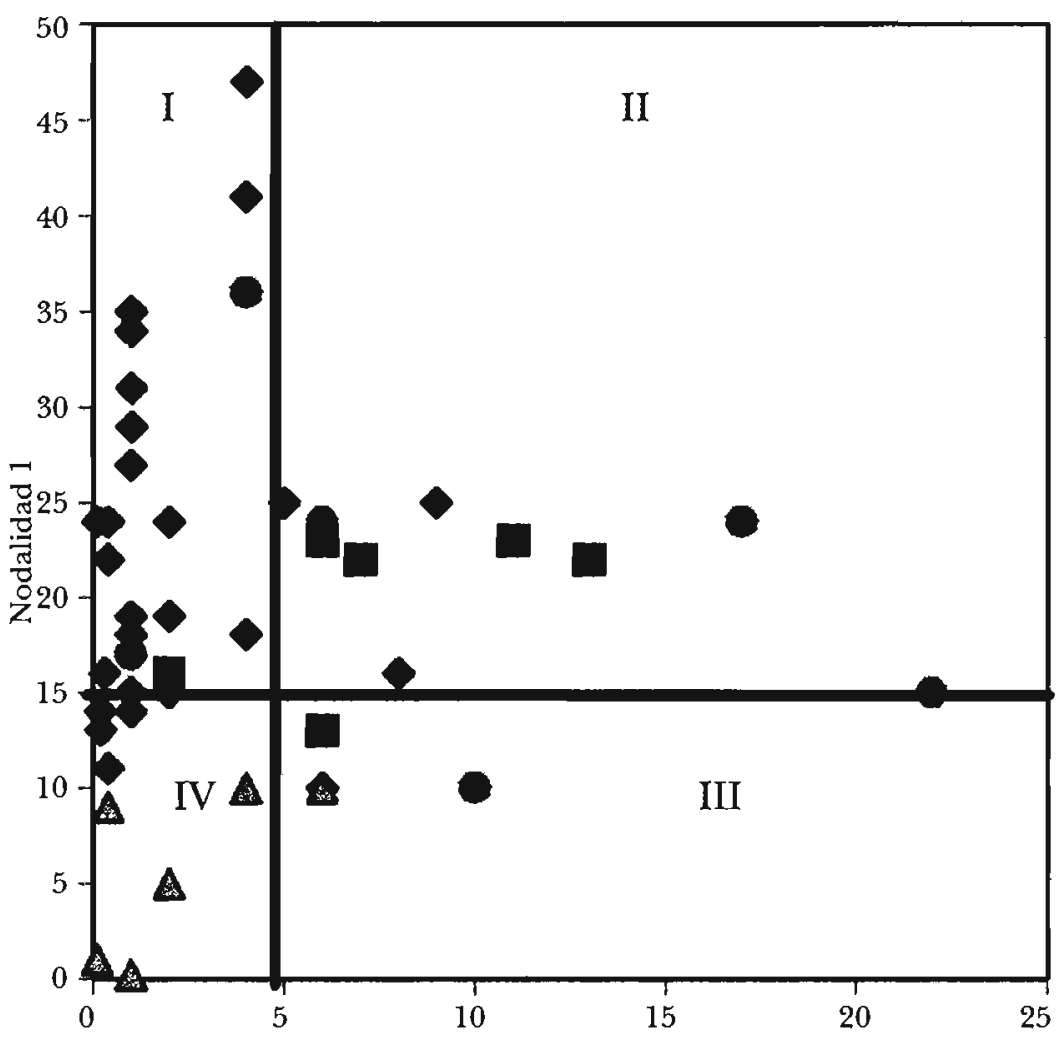

Monocéntrica

Bifuncional

Policéntrica

A Competitiva

Nodalidad 2 
estructura bifuncional o policéntrica y acogen a las metrópolis con mayor tamaño de población (Ciudad de México, Guadalajara, Monterrey, Puebla y Toluca). El cuadrante III (complementariedad) contiene el menor número de casos con cuatro ciudades (Saltillo, Torreón, Ocotlán y Tlaxcala), que sin definición hacia algún tipo de estructura ocupacional metropolitana, muestran un importante flujo del centro hacia la periferia, la cual se especializa en demanda ocupacional en la industria. Por último, en la situación del cuadrante IV (dualismo) aparecen nueve metrópolis y predominan las que cuentan con una estructura ocupacional con mercados competitivos.

Los cuadrantes II, III y IV representan variaciones al patrón centralizado de flujos intrametropolitanos por motivo de trabajo. Con tal precedente la conclusión que se desprende es que $46 \%$ de las metrópolis del país ( 22 de 48 ) presenta algún patrón multinodal de desplazamientos, en tanto que el $54 \%$ restante ( 26 de 48 ) se caracteriza por contener un patrón de viajes tradicional, en donde la ciudad central es la unidad territorial con la mayor recepción de población ocupada. Se espera que con el paso del tiempo cada vez exista una menor cantidad de metrópolis con un patrón tradicional de viajes por motivo de trabajo, esperanza que se basa en el tránsito de las etapas de metropolitanismo por las que evoluciona cada zona metropolitana.

Para investigar las causas que explican el patrón de viajes de cada zona metropolitana se corrieron dos funciones de regresión múltiple con el procedimiento stepwise: en la primera se utilizó como variable dependiente el valor de $\mathrm{N} 1$ y como independientes a: $i$ ) el tamaño de la población (POBLACIÓN); ii) el número de municipios periféricos (MUNICIPIOS); iii) el porcentaje de la población ocupada en la industria (INDUSTRIA); iv) el porcentaje de la población ocupada en el comercio (COMERCIO); $v$ ) el porcentaje de la población ocupada en los servicios (SERVICIOS), y vi) la comparación entre la tasa de crecimiento poblacional 1990-2000 del municipio central y la de los municipios periféricos, indicador de la etapa de metropolitanismo (ETAPA). En la segunda regresión se mantuvieron las mismas variables independientes, pero la dependiente se cambió por el valor de N2 (véase el cuadro 4).

Los movimientos intrametropolitanos periferia-centro medidos por N1 se explican por las variables COMERCIO y ETAPA. Esto significa que cuanto más exhiban las metrópolis mexicanas un proceso de suburbanización, habrá mayor cantidad de desplazamientos por motivo de trabajo de la periferia al centro, siempre y cuando la metrópoli en cuestión se especialice en actividades comerciales. 
CUADRO 4

Variables explicativas de la nodalidad

\begin{tabular}{|c|c|c|c|c|}
\hline Variable & $\begin{array}{c}\beta \\
\text { estandarizada }\end{array}$ & $t$ & Significancia & $V F$ \\
\hline \multicolumn{5}{|c|}{ Nodalidad 1} \\
\hline COMERCIO & 0.308 & 2.555 & 0.014 & 1.016 \\
\hline ETAPA & -0.475 & -3.938 & 0.000 & 1.016 \\
\hline \multicolumn{5}{|c|}{ Nodalidad 2} \\
\hline POBLACIÓN & 0.636 & 5.842 & 0.000 & 1.033 \\
\hline ETAPA & -0.189 & -1.735 & 0.090 & 1.033 \\
\hline
\end{tabular}

Fuente: Funciones de regresión con el método stepruise.

Por su parte el movimiento contrario, centro-periferia, estimado por N2, tiene como variables explicativas a la POBLACIÓN y la ETAPA. Como se observa, en ambas regresiones la variable ETAPA adquirió notación relevante, pero en este caso, el mayor flujo de trabajadores que viven en la ciudad central y trabajan en la periferia se explica por el grado de suburbanización que alcanza la metrópoli, pero tambiên por su tamaño de población. Así, a mayor suburbanización y especialización ocupacional en el comercio, mayor desplazamiento periferiacentro; a mayor suburbanización y tamaño de población, mayor desplazamiento centro-periferia. De esta manera, el cambio en la estructura económica de las zonas metropolitanas en México desde una tipología tradicional con especialización en el comercio hacia otra más avanzada con predominio de las ạctividades de servicios superiores, será acompañada por una transformación en los patrones intrametropolitanos de los viajes por motivo de trabajo, con énfasis en la descentralización.

\section{Conclusiones}

Hacia mediados del siglo $\mathrm{xx}$ la existencia de grandes zonas metropolitanas era asunto casi exclusivo de las naciones desarrolladas, y su grado de urbanización conjunto era superior a 50\%; en el ciclo del desarrollo urbano sus sistemas urbanos atravesaban por una fase de polarización regresiva, en tanto que en sus microrregiones urbanas funcionales se 
evidenciaba la etapa de metropolitanismo de suburbanización (Fielding, 1989; Korcelli, 1984; Vining y Kontuly, 1978). Esto significa que las ciudades centrales iban perdiendo participación demográfica, tanto en comparación con el sistema urbano nacional como con su sistema urbano cotidiano. Fue en este escenario donde los gobiernos centrales de un buen número de esos países empezaron a establecer lineamientos normativos para la delimitación operativa de las zonas metropolitanas; tales esfuerzos en un principio sirvieron para diferenciar el ámbito urbano del rural en las inmediaciones de las grandes ciudades, así como para incrementar la disponibilidad de información sobre este tipo de aglomeraciones económico demográficas. Posteriormente la delimitación normativa se utilizó para establecer mecanismos de planeación territorial y de prestación de servicios públicos, llegando, incluso, en la década de los ochenta a la creación de instancias de gobierno y administración para el ámbito metropolitano.

En la segunda mitad del siglo la expansión urbana fue mucho más significativa en los países en desarrollo y, por ejemplo, en Latinoamérica el grado de urbanización avanzó de menos de $40 \%$ en 1950 a más de $70 \%$ en 2000 . En ellos se combinó un explosivo crecimiento demográfico (Preston, 1988) con una fase en el ciclo de desarrollo urbano de concentración o primacía (Brown y Stetzer, 1984; Gilbert, 1993), aspectos que condujeron a la aparición de un puñado de grandes metrópolis en el mundo en desarrollo, entre los cuales generalmente descollaba la capital del país, lo cual evidenciaba las etapas de metropolización hacia la suburbanización.

Sin embargo, en la mayoría de estos países no existen criterios oficiales para la delimitación de metrópolis. En los estudios urbanoregionales de México se reconoce, generalmente, que una zona metropolitana es un conjunto de unidades político administrativas (municipios) que contienen una ciudad central y localidades periféricas unidas o interrelacionadas a la primera. Por su parte, en la perspectiva oficial gubernamental el fenómeno de conurbación se ha asociado con la continuidad física y demográfica que forman o tienden a formar dos o más centros de población situados en territorios municipales distintos, en tanto que en la LGAH de 1993 se entiende por zona metropolitana un espacio territorial de influencia dominante de un centro de población o, de acuerdo con el glosario de términos del Programa de Desarrollo Urbano 2001-2006, un área urbana que presenta procesos diferenciados de "metropolización" entre ciudades fronterizas o entre ciudades de dos o más entidades federativas, así 
como aquellas grandes ciudades que tienen más de un millón de habitantes. Como se observa, el concepto que se maneja en las instancias gubernamentales es menos preciso que en el mundo académico, además de que no se han propuesto, como en otros países, criterios normativos para la delimitación del espectro metropolitano. Esto, indudablemente, constituye un reto a vencer por parte de los gobiernos en sus distintos estratos durante los primeros años del presente siglo.

El fenómeno de metropolización en México evolucionó de manera ininterrumpida en la segunda mitad del siglo XX, al aumentar las conurbaciones de cinco en 1950 a 48 en 2000; esta multiplicación de metrópolis se acompañó hasta 1960 con una fase en el ciclo del desarrollo urbano de concentración, y de polarización regresiva, de 1960 a la fecha. En 2000 la Ciudad de México concentró $18.6 \%$ de la población del país y su ritmo de crecimiento fue inferior que el total nacional; por otro lado, desde 1980 paulatinamente fue perdiendo participación en su contribución económica, pero en 1998 aún representó $32.5 \%$ del producto interno bruto nacional, es decir casi una tercera parte.

Uno de los propósitos que se persiguieron en este documento fue proponer el número y la conformación de las zonas metropolitanas de México en 2000, utilizando una variable que por primera vez ofrece el censo de población: los viajes intermunicipales por motivo de trabajo. Con ella, y con los parámetros cuantitativos utilizados, se llegó a la delimitación de 48 zonas metropolitanas. A diferencia de otras propuestas académicas en donde la delimitación se realiza valiéndose de la conformación de microrregiones urbanas homogéneas, en ésta la variable dinámica viajes por motivo de trabajo permite contar con un estimador menos indirecto del criterio de interrelación funcional, el cual nos acerca más a la delimitación de microrregiones urbanas funcionales.

El uso de la variable viajes por motivo de trabajo para la delimitación de zonas metropolitanas fue convincente porque de las 48 en que se obtuvo, sólo Tuxtla Gutiérrez, Tehuacán, San Juan del Río, Piedras Negras, Tulancingo, Teziutlán, Salina Cruz, Ocotlán y Cozumel no se habían considerado como tales en alguna otra propuesta académica o delimitación enunciada en los programas nacionales de desarrollo urbano. Al mismo tiempo, la conformación de algunas metrópolis con el mecanismo de microrregiones urbanas funcionales resultó más extensa que con el uso de otros, ya que, por ejemplo, para la Ciudad de México se habían considerado 41 municipios conurbados (Negrete, 2000), mientras que aquí se obtuvieron 47; en Monterrey se habían 
contabilizado ocho municipios periféricos en 1990 (Garza, 1995) y este ejercicio arrojó 14 para 2000. Corresponderá a otros estudios explicar el porqué de la mayor extensión en la delimitación de zonas metropolitanas utilizando la variable viajes por motivo de trabajo.

Se debe tomar en cuenta que la conformación metropolitana de México se complementa con las conurbaciones binacionales TijuanaSan Diego, Mexicali-Calexico, Nogales-Nogales, Agua Prieta-Douglas, Ciudad Juárez-El Paso, Ciudad Acuña-Del Río, Piedras Negras-Eagle Pass, Nuevo Laredo-Laredo, Reynosa-McAllen y Matamoros-Brownsville. En estos pares de ciudades se desenvuelven procesos transfronterizos de carácter territorial, movimientos de población, flujos económicos y problemas de cohesión social (Alegría, 1992). La comprensión de estos elementos permite entender mejor la relación particular que existe entre la frontera y la conformación de su espacio urbano.

Para enriquecer los propósitos del documento se analizaron las matrices de viajes por motivo de trabajo que se construyeron para cada zona metropolitana, y así se estableció una tipología sobre la estructura ocupacional y los patrones de viaje de cada metrópoli. Se debe resolver la interrogante sobre la pertinencia o no de ubicar como entes metropolitanos a León, Tijuana, Saltillo, Cancún, Guaymas y Cozumel. A reserva de un mayor análisis, todo parece indicar que León sí se puede considerar zona metropolitana dada la especialización en la producción de calzado tanto de ese municipio como de Purísima del Rincón y San Francisco del Rincón, amén del considerable flujo de trabajadores de Silao hacia León; Cancún y Cozumel también, por su interrelación funcional turística, aunque en ellas la fricción de la distancia que impone la separación del mar Caribe en los municipios conurbados condiciona fuertemente los desplazamientos por motivo de trabajo; Saltillo y Guaymas pueden aprobar el examen debido a la magnitud del flujo de trabajadores desde el municipio central hacia el periférico. Por tanto, la mayor duda se refiere a Tijuana.

El mayor número de zonas metropolitanas en México contiene una estructura ocupacional de tipo monocéntrico, que se caracteriza por un mayor número de población ocupada en el municipio central respecto al volumen de PEA de dicho municipio. Esta tipología se acompaña con un mayoritario patrón de viajes periferia-centro. Sin embargo, más de $40 \%$ de las metrópolis tienen un patrón de viajes distinto, presentando variaciones del flujo tradicional, lo que habla de procesos de descentralización intrametropolitana de las activida- 
des económicas y que se relacionan con la etapa de metropolitanismo y el tamaño de población de la zona. Así, el sistema metropolitano del país no es homogéneo, por lo que nuevos estudios deberán destacar las particularidades de cada subconjunto de metrópolis que compartan, por ejemplo, una similar estructura ocupacional o cierto rango poblacional.

Las funciones de regresión que se corrieron para explicar la nodalidad 1 y nodalidad 2 concluyeron que a mayor suburbanización y especialización ocupacional en comercio, mayor desplazamiento periferia-centro, mientras que a mayor suburbanización y tamaño de población, mayor desplazamiento centro-periferia. El hipotético cambio a futuro en la estructura económica de las zonas metropolitanas en México, desde una tipología tradicional y especializada en comercio hacia otra moderna o más avanzada con predominio de las actividades de servicios superiores, será acompañada, muy probablemente, por una transformación en los patrones intrametropolitanos de los viajes por motivo de trabajo, con tendencia hacia a la descentralización. 


\section{CUADRO Al}

\section{Conformación de las zonas metropolitanas de México, 2000}

\begin{tabular}{|c|c|c|c|c|c|c|c|c|c|c|c|c|c|c|c|c|c|c|}
\hline \multirow[b]{3}{*}{ Nim } & \multirow[b]{3}{*}{ Clave } & \multirow{3}{*}{\multicolumn{2}{|c|}{ Tipo Nombre }} & \multicolumn{3}{|c|}{ Caräcler urbano } & \multicolumn{5}{|c|}{ Integración funcional } & \multicolumn{5}{|c|}{ Dinamica demográfica } & \multicolumn{2}{|c|}{ Importancia económice } \\
\hline & & & & \multirow{2}{*}{$\begin{array}{c}\text { Población } \\
2000\end{array}$} & \multirow{2}{*}{$\begin{array}{c}\text { Población } \\
\text { urbana } \\
2000\end{array}$} & \multirow{2}{*}{$\begin{array}{l}\text { Grado } \\
\text { de urba- } \\
\text { nización }\end{array}$} & \multirow{2}{*}{$\begin{array}{l}\text { PEA } \\
\text { total }\end{array}$} & \multicolumn{2}{|c|}{ VPT origen } & \multicolumn{2}{|c|}{ VPT destino } & \multicolumn{5}{|c|}{ Tasas de crecimiento inlercensal } & \multirow{2}{*}{$\begin{array}{l}\text { VBP told } \\
1998 \text { (millo- } p \\
\text { nes de pesos) }\end{array}$} & \multirow{2}{*}{$\begin{array}{c}B P \\
\text { per cippila } \\
\text { (pesos) }\end{array}$} \\
\hline & & & & & & & & Total & $\%$ & Total & $\%$ & $50-60$ & $60-70$ & $70-80$ & $80-90$ & 9000 & & \\
\hline 1 & & & Ciudad de Mexica & 18180183 & 17874908 & 98.3 & 6762424 & 2587341 & 38.3 & 2587341 & 42.9 & 4.92 & 5.26 & 4.38 & 0.75 & 1.68 & 8736.95 & 48058 \\
\hline 1 & 9014 & 1 & Benito Juárez & 360478 & 360478 & 100.0 & 169162 & 79252 & 46.8 & 190158 & 70.6 & 4.17 & 1.26 & -1.02 & -2.92 & -1.24 & 57141 & 158514 \\
\hline 2 & 9015 & I & Cuauhtémoc & 516255 & 516255 & 100.0 & 225977 & 80003 & 35.4 & 431169 & 76.4 & 0.18 & -1.50 & -1.24 & -3.15 & -1.44 & 83959 & 162632 \\
\hline 3 & 9016 & 1 & Miguel Hidalgo & 352640 & 352640 & 100.0 & 152641 & 51383 & 33.7 & 228982 & 71.3 & 3.64 & -0.04 & -1.70 & -2.91 & -1.43 & 1.50541 & 426898 \\
\hline 4 & 9017 & 1 & Venustiano Carranza & 462806 & 462806 & 100.0 & 187140 & 87213 & 46.6 & 114350 & 56.9 & 4.47 & 2.44 & -0.39 & -2.90 & -1.16 & 16664 & 36006 \\
\hline 5 & 9002 & 2 & Azcapoualco & 441008 & 441008 & 100.0 & 177362 & 73590 & 41.5 & 114472 & 56.2 & 7.03 & 3.87 & 1.15 & -2.39 & -0.74 & 66947 & 151805 \\
\hline 6 & 9003 & 2 & Coyoacán & 640423 & 640423 & 100.0 & 273158 & 126466 & 46.3 & 156650 & 55.6 & 9.26 & 7.45 & 5.61 & 0.71 & 0.01 & 33170 & 51794 \\
\hline 7 & 9004 & 2 & Cuajimalpa de Morelos & 151222 & 151222 & 100.0 & 58624 & 20390 & 34.8 & 27059 & 44.1 & 7.09 & 6.80 & 9.34 & 2.82 & 2.39 & 8245 & 54522 \\
\hline 8 & 9005 & 2 & Gustavo A. Madero & 1295542 & 1235542 & 100.0 & 482143 & 193458 & 40.1 & 157785 & 39.2 & 10.95 & 7.72 & 2.98 & -1.79 & -0.26 & 26145 & 21161 \\
\hline 9 & 9006 & 2 & Iztacalco & 411321 & 411321 & 100.0 & 167018 & 82782 & 49.6 & 78394 & 53.5 & 19.33 & 9.50 & 1.74 & -2.49 & -0.86 & 19755 & 48027 \\
\hline 10 & 9007 & 2 & Izlapalapa & 1773343 & 1773343 & 100.0 & 681957 & 273719 & 40.1 & 160734 & 31.6 & 12.74 & 7.74 & 8.90 & 1.71 & 1.77 & 44808 & 25267 \\
\hline 11 & 9008 & 2 & Magdalena Contreras, La & 222050 & 222050 & 100.0 & 89043 & 44642 & 50.1 & 21360 & 36.2 & 6.37 & 6.60 & 8.36 & 1.23 & 1.32 & 3219 & 14495 \\
\hline 12 & 9009 & 2 & Milpa Alla & 96773 & 96779 & 100.0 & 34896 & 13771 & 39.5 & 9780 & 39.9 & 2.96 & 3.41 & 4.59 & 1.77 & 4.31 & 258 & 2669 \\
\hline 13 & 9010 & 2 & Álvaro Obregón & 687020 & 687020 & 100.0 & 278599 & 118022 & 40.6 & 119908 & 45.2 & 8.97 & 7.87 & 3.30 & 0.06 & 0.67 & 45275 & 65900 \\
\hline 14 & 9011 & 2 & Tláhuac & $\$ 02790$ & 302790 & 100.0 & 109619 & 52953 & 48.3 & 24458 & 33.2 & 4.35 & 7.94 & 8.62 & 3.56 & 3.92 & 3268 & 10794 \\
\hline 15 & 9012 & 2 & Tlalpan & 581781 & 581781 & 100.0 & 237707 & 94584 & 39.8 & 112376 & 46.9 & 6.44 & 8.19 & 10.54 & 2.84 & 1.85 & 23304 & 40056 \\
\hline 16 & 9013 & 2 & Xochimilco & 369787 & 369787 & 100.0 & 141707 & 56701 & 40.0 & 88593 & 33.9 & 4.10 & 5.37 & 6.22 & 2.28 & 3.18 & 11584 & 31327 \\
\hline 171 & 13013 & 2 & Atotonilco de Tula & 24848 & 16238 & 65.3 & 7787 & 901 & 11.6 & 26 & 0.5 & -7.03 & 3.34 & 4.04 & 2.97 & 2.56 & 1672 & 67283 \\
\hline 18 & 13069 & 2 & Tizayuca & 46344 & 40162 & 86.7 & 16968 & 2361 & 13.9 & 7036 & 35.5 & 1.71 & 3.87 & 6.35 & 6.45 & 4.38 & 2506 & 54065 \\
\hline 191 & 15002 & 2 & Acolman & 61250 & 55747 & 91.0 & 19988 & 7026 & 35.2 & 3312 & 23.4 & 2.64 & 5.75 & 4.27 & 3.03 & 3.56 & 1841 & 30065 \\
\hline 20 & 15009 & 2 & Arnecameca & 45255 & 29949 & 66.2 & 14362 & 2149 & 15.0 & 1282 & 11.1 & 2.20 & 2.81 & 3.59 & 1.43 & 2.24 & 127 & 2808 \\
\hline 211 & 15011 & 2 & Atenco & 34435 & 26371 & 76.6 & 11184 & 4177 & 37.3 & 915 & 13.0 & 3.07 & 3.90 & 4.30 & 2.66 & 5.00 & 155 & 4500 \\
\hline 221 & 15013 & 2 & Alizapán de Zaragoza & 467886 & 467544 & 99.9 & 164278 & 68672 & 41.8 & 9412 & 10.7 & 5.27 & 19.33 & 15.80 & 4.65 & 4.06 & 6061 & 12954 \\
\hline 23 & 15020 & 2 & Coacalco de Berriozábal & 252555 & 252291 & 99.9 & 86847 & 42694 & 49.2 & 12811 & 28.2 & 5.58 & 13.23 & 21.30 & 4.67 & 5.24 & 1683 & 6663 \\
\hline 24 & 15022 & 2 & Cocoùlán & 10205 & 8624 & 84.5 & 3456 & 1481 & 42.8 & 134 & 8.3 & 1.80 & 3.31 & 4.02 & 0.74 & 2.40 & 11 & 1055 \\
\hline 251 & 15023 & 2 & Coyotepec & 35358 & 31623 & 89.4 & 10802 & 5463 & 50.6 & 686 & 13.7 & 2.93 & 4.22 & 8.04 & 2.19 & 3.79 & 43 & 1220 \\
\hline 261 & 15024 & 2 & Cuautitlán & 75836 & 69312 & 91.4 & 25729 & 11468 & 44.6 & 28065 & 68.8 & 4.17 & 7.49 & -0.39 & 2.19 & 4.53 & 8718 & 114958 \\
\hline 27 & 15025 & 2 & Chalco & 217972 & 200415 & 91.9 & 66385 & 19393 & 29.2 & 14632 & 27.7 & 3.03 & 3.51 & 6.35 & 14.04 & -2.59 & 2165 & 9931 \\
\hline
\end{tabular}




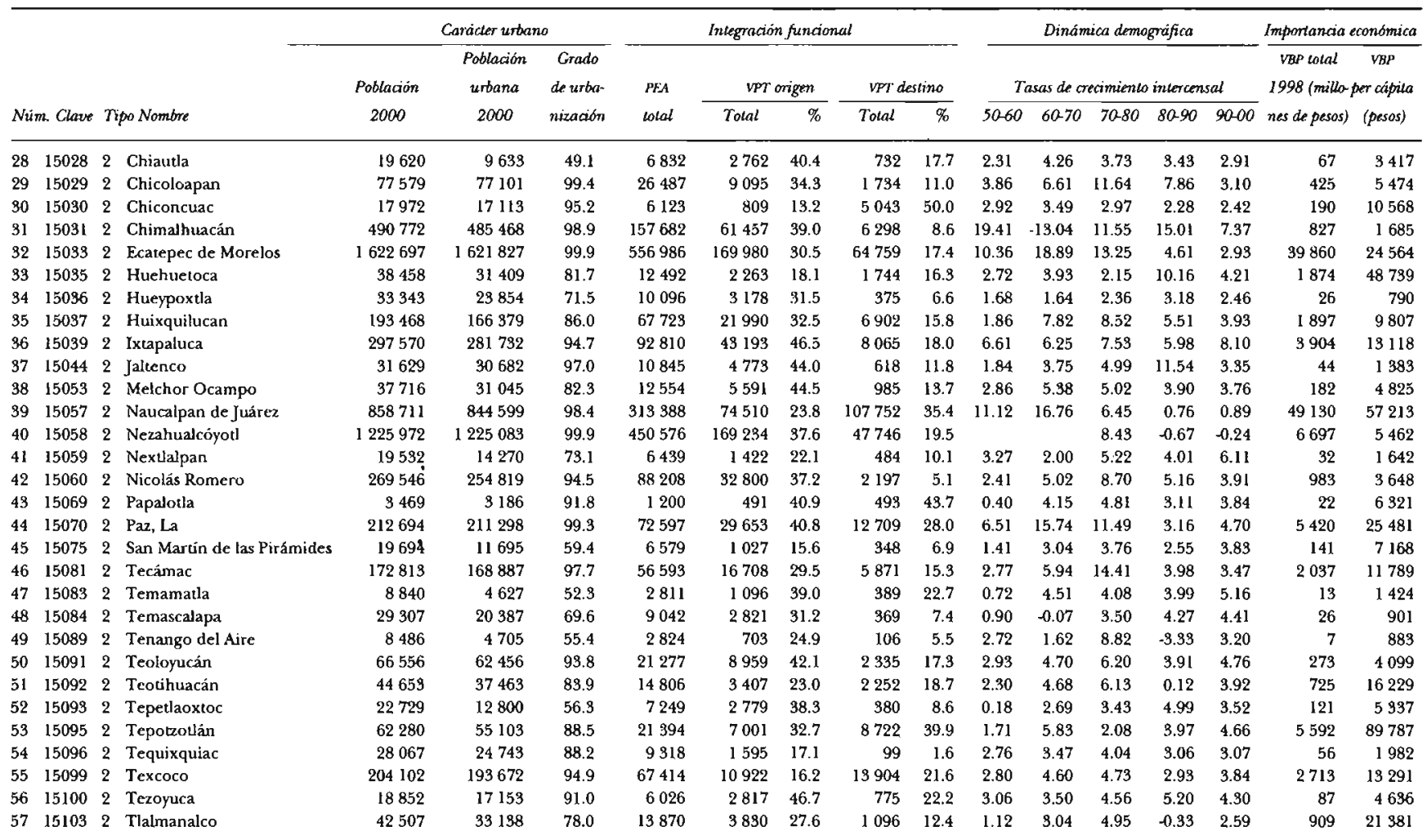


$\begin{array}{llll}58 & 15104 & 2 & \text { Tlalnepanda de Baz }\end{array}$

$\begin{array}{llll}59 & 15108 & 2 & \text { Tultepec }\end{array}$

$\begin{array}{llll}60 & 15109 & 2 & \text { Tultitán }\end{array}$

61 $15120 \quad 2$ Zumpango

62151212 Cuautitân lzcalli

63151222 Valle de Chalco Solidaridad

$$
2
$$

$\begin{array}{llll}1 & 14039 & 1 & \text { Guadalajara }\end{array}$

2140022 Acatlán de Juárez

3140092 Arenal, El

4140442 lxulahuacán de los Membrillos

5140512 Juanacatlán

$614070 \quad 2$ Salto, E]

$\begin{array}{llll}7 & 14097 & 2 & \text { Tlajomulco de Zúñiga }\end{array}$

$\begin{array}{llll}8 & 14098 & 2 & \text { Tlaquepaque }\end{array}$

9141012 Tonalá

$10 \quad 14120 \quad 2$ Zapopan

3

$1 \quad 190391$ Monterrey

2190062 Apodaca

3190102 Carmen

4190122 Ciénega de Flores

5190182 García

$6 \quad 190192$ San Pedro Garza García

7190212 General Escobedo

8190252 General Zuazua

9190262 Guadalupe

$\begin{array}{llll}10 & 19081 & 2 & \text { Juárez }\end{array}$

$11 \quad 190342$ Marín

121904122 Pesquería

$1919045 \quad 2$ Salinas Victoria

14190462 San Nicolás de los Carza

$15 \quad 19048 \quad 2$ Santa Catarina

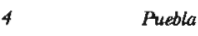

I 21114 I Puebla

\begin{tabular}{|c|c|c|c|c|c|c|c|c|c|c|c|c|c|c|}
\hline 721415 & 721407 & 100.0 & 262519 & 98426 & 87.5 & 151843 & 54.2 & 18.77 & 13.81 & 7.53 & -1.04 & 0.26 & 74037 & 102627 \\
\hline 93277 & 87341 & 93.6 & 29646 & 15148 & 51.1 & 2936 & 20.4 & 3.45 & 4.17 & 6.90 & 7.71 & 7.08 & 1947 & 20871 \\
\hline 432141 & 428163 & 99.1 & 144969 & 60285 & 41.6 & 24268 & 25.9 & 5.30 & 13.46 & 9.73 & 6.21 & 5.82 & 10547 & 24406 \\
\hline 99774 & 84595 & 84.8 & 32298 & 7798 & 24.1 & 4689 & 18.6 & 2.63 & 4.94 & 3.47 & 3.42 & 3.43 & 464 & 4650 \\
\hline 453298 & 450776 & 99.4 & 158017 & 51710 & 32.7 & 31900 & 25.8 & & & & 6.68 & 3.95 & 41821 & 92260 \\
\hline 323461 & 322784 & 99.8 & 108200 & 47394 & 43.8 & 2384 & 5.6 & & & & & & 1336 & 4180 \\
\hline 3733895 & 3643177 & 97.6 & 1438106 & 297464 & 20.7 & 297464 & 21.2 & 6.38 & 5.54 & 4.06 & 2.60 & 2.13 & 207960 & 55695 \\
\hline 1646319 & 1646183 & 100.0 & 659842 & 61815 & 9.4 & 170704 & 22.5 & 6.89 & 5.13 & 2.98 & 0.15 & -0.02 & 89020 & 54072 \\
\hline 20236 & 17963 & 88.8 & 6596 & 1584 & 24.0 & 185 & 3.9 & 3.12 & 1.83 & 2.85 & 0.34 & 3.45 & 253 & 12483 \\
\hline 14523 & 9796 & 67.5 & 4764 & 956 & 20.1 & 163 & 4.4 & 2.69 & 3.95 & 2.20 & 2.49 & 2.27 & 100 & 6873 \\
\hline 21605 & 10564 & 48.9 & 7263 & 1430 & 19.7 & 239 & 4.2 & 1.76 & 3.45 & 1.41 & 3.15 & 2.64 & 2127 & 98427 \\
\hline 11792 & 8117 & 68.8 & 4047 & 1779 & 44.0 & 262 & 10.7 & 0.99 & 0.48 & 3.79 & 2.28 & 1.61 & 18 & 1514 \\
\hline 83453 & 81437 & 97.6 & 27972 & 5065 & 18.1 & 19056 & 46.0 & 0.84 & 3.33 & 4.70 & 6.93 & 8.17 & 48041 & 575670 \\
\hline 123619 & 96113 & 77.7 & 42724 & 11011 & 25.8 & 10097 & 24.6 & 3.48 & 3.09 & 3.60 & 3.12 & 6.14 & 11192 & 90539 \\
\hline 474178 & 471516 & 99.4 & 170627 & 57017 & 33.4 & 28809 & 21.1 & 5.41 & 6.26 & 5.59 & 6.88 & 3.42 & 11990 & 25287 \\
\hline 337149 & 325772 & 96.6 & 124776 & 50497 & 40.5 & 11802 & 14.5 & 3.29 & 4.67 & 7.51 & 12.76 & 7.23 & 1595 & 4791 \\
\hline 1001021 & 975716 & 97.5 & 389495 & 106310 & 27.8 & 56148 & 17.1 & 7.24 & 11.47 & 9.27 & 6.98 & 3.49 & 43624 & 43579 \\
\hline 3302411 & 3255300 & 98.6 & 1248483 & 437908 & 35.1 & 437908 & 36.0 & 6.19 & 5.84 & 4.66 & 2.54 & 2.40 & 244556 & 74054 \\
\hline 1110997 & 1110909 & 100.0 & 428429 & 70930 & 16.6 & 185623 & 34.7 & 5.88 & 3.76 & 2.34 & -0.20 & 0.39 & 93614 & 84261 \\
\hline 289497 & 273964 & 96.6 & 104248 & 48448 & 46.5 & 44785 & 45.7 & 2.45 & 11.94 & 6.94 & 12.34 & 9.43 & 25916 & 91415 \\
\hline 6644 & 5936 & 89.3 & 2400 & 429 & 17.9 & 858 & 31.3 & 1.66 & 5.60 & 6.00 & 2.29 & 8.10 & 1610 & 242390 \\
\hline 11204 & 10261 & 91.6 & 4105 & 642 & 15.6 & 3230 & 49.2 & 2.67 & 4.84 & 4.33 & 2.90 & 5.90 & 253 & 22560 \\
\hline 28974 & 25059 & 86.5 & 9389 & 2488 & 26.0 & 10864 & 61.3 & -1.52 & 4.88 & 4.71 & 2.41 & 8.27 & 6969 & 240528 \\
\hline 125978 & 125945 & 100.0 & 49205 & 18989 & 38.6 & 48442 & 62.3 & 11.07 & 12.37 & 5.74 & 8.34 & 1.10 & 20721 & 164483 \\
\hline 233457 & 230556 & 98.8 & 81864 & 41629 & 50.9 & 13875 & 27.3 & -1.24 & 19.93 & 13.15 & 10.27 & 9.12 & 6295 & 26965 \\
\hline 6033 & 5266 & 87.3 & 2406 & 377 & 15.7 & $\$ 44$ & 15.1 & -0.71 & 5.77 & 4.03 & 1.43 & 2.66 & 2235 & 370430 \\
\hline 670162 & 669842 & 100.0 & 255332 & 110540 & 43.3 & 36890 & 21.3 & 11.72 & 16.00 & 8.47 & 3.83 & 2.28 & 15589 & 23261 \\
\hline 66497 & 53822 & 80.9 & 22183 & 13588 & 61.3 & 3008 & 28.4 & 1.10 & 6.20 & 8.76 & 7.77 & 9.10 & 629 & 9464 \\
\hline 4719 & 3068 & 65.0 & 1765 & 428 & 24.2 & 417 & 24.4 & -0.56 & 3.79 & 3.85 & 2.52 & 3.69 & 29 & 6205 \\
\hline I 1321 & 5290 & 46.7 & 4093 & 1154 & 28.2 & 1315 & 31.3 & -3.02 & 5.11 & 2.90 & 1.67 & 3.32 & 446 & 39373 \\
\hline 19024 & 12528 & 65.9 & 6665 & 1285 & 19.3 & 1799 & 26.0 & -0.18 & 1.47 & 4.94 & 0.36 & 7.23 & 936 & 49189 \\
\hline 496878 & 496878 & 100.0 & 189739 & 88942 & 46.9 & 66911 & 40.8 & 14.61 & 11.03 & 9.18 & 4.63 & 1.31 & 50057 & 100742 \\
\hline 227026 & 225976 & 99.5 & 86660 & 38088 & 44.0 & 19547 & 29.4 & 5.74 & 11.96 & 9.08 & 6.39 & 3.34 & 19257 & 84825 \\
\hline 1837168 & 1727717 & 94.0 & 652431 & 34855 & 5.3 & 34855 & 5.7 & 12.64 & 5.16 & 4.29 & 2.64 & 2.67 & 93901 & 51112 \\
\hline 1346916 & 1304527 & 96.9 & 492068 & 5632 & 1.1 & 29154 & 4.7 & 28.89 & 6.24 & 4.45 & 2.44 & 2.47 & 39232 & 29128 \\
\hline
\end{tabular}




\section{CUADRO 1A (continuación)}

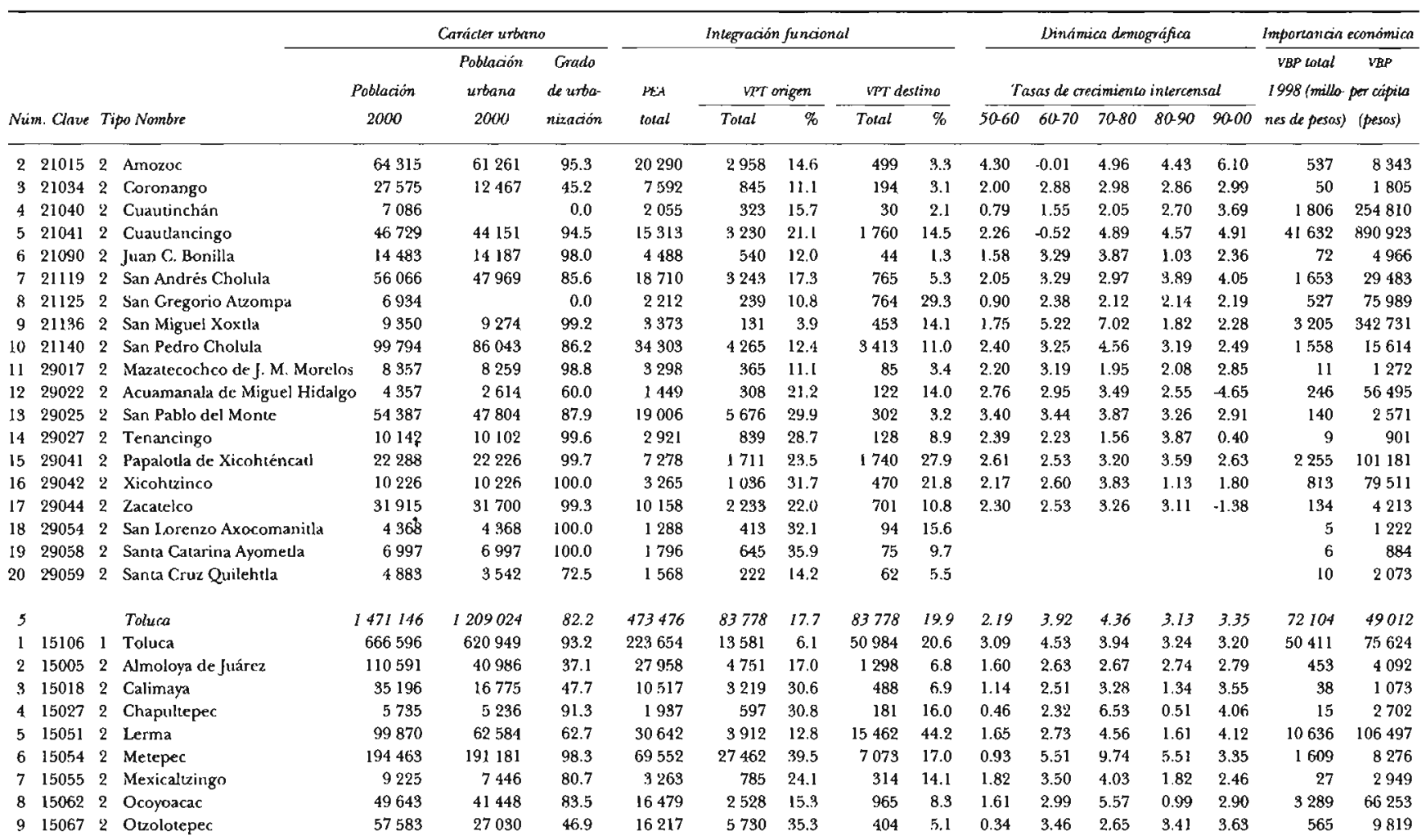




\begin{tabular}{|c|c|c|c|c|c|c|c|c|c|c|c|c|c|c|c|c|c|c|}
\hline 10 & 15072 & 2 & Rayón & 9024 & 6689 & 74.1 & 2962 & 641 & 21.6 & 223 & 11.5 & 1.43 & 2.35 & 3.89 & 2.19 & 2.55 & 22 & 2391 \\
\hline 11 & 15073 & 2 & San Antonio la Isla & $10 \$ 21$ & 9994 & 96.8 & 3247 & 796 & 24.5 & 374 & 14.7 & 0.39 & 4.45 & 8.08 & .264 & 3.52 & 334 & 32328 \\
\hline 12 & 15076 & 2 & San Mateo Acenco & 59647 & 57440 & 96.3 & 19894 & 3981 & 17.0 & 3540 & 18.7 & 2.65 & 4.39 & 6.17 & 2.25 & 3.62 & 3957 & 56283 \\
\hline 13 & 15115 & 2 & Xonacalán & 41402 & 26524 & 641 & 19093 & 2016 & 15.4 & 940 & 12.3 & 2.13 & 3.84 & 2.44 & 4.06 & 3.71 & 107 & 2594 \\
\hline 14 & 15118 & 2 & Zinacantepec & 121850 & 94742 & 77.8 & 34061 & 14379 & 42.2 & 1534 & 9.1 & 1.98 & 3.50 & 3.04 & 3.36 & 3.92 & 1241 & 10181 \\
\hline 6 & & & Laón & 1414196 & 1217527 & 86.1 & 510474 & 16237 & 3.2 & 16237 & 3.2 & 4.07 & 4.39 & 3.80 & 2.99 & 2.59 & 70838 & 50090 \\
\hline 1 & 11020 & $\mathbf{1}$ & León & 1134842 & 1058020 & 93.2 & 420186 & 6563 & 1.6 & 4726 & 1.1 & 5.17 & 5.08 & 4.40 & 2.91 & 2.74 & 32725 & 28837 \\
\hline 2 & 11025 & 2 & Purísima del Rincón & 44778 & 25274 & 56.4 & 15524 & 4394 & 28.3 & 1202 & 9.8 & 1.46 & 2.20 & 2.50 & 2.81 & 3.97 & 1022 & 22827 \\
\hline 3 & 11031 & 2 & San Francisco del Rincón & 100239 & 65183 & 65.0 & 35698 & 1356 & 3.8 & 9421 & 21.7 & 1.71 & 2.28 & 2.79 & 2.36 & 1.85 & 2939 & 29318 \\
\hline 4 & 11037 & 2 & Silao & 134337 & 69050 & 51.4 & 39066 & 3924 & 10.0 & 888 & 2.6 & 2.08 & 2.88 & 0.79 & 4.20 & 1.57 & 34151 & 254222 \\
\hline 7 & & & Tijuana & 1274240 & 1253251 & 98.4 & 438075 & 3493 & 0.8 & 3493 & 0.8 & $9.7 d$ & 7.76 & 2.97 & 5.06 & 5.52 & 43689 & 34286 \\
\hline 1 & 2004 & 1 & Tijuana & 1210820 & 1196684 & 98.8 & 418959 & 1877 & 0.4 & 1616 & 0.4 & 9.74 & 7.76 & 2.97 & 5.06 & 4.98 & 42878 & 95413 \\
\hline 2 & 2005 & 2 & Playas de Rosarito & 69420 & 56567 & 89.2 & 19116 & 1616 & 8.5 & 1877 & 9.8 & & & & & & 810 & 12778 \\
\hline 8 & & & mesón & 1007291 & 859145 & 85.3 & 360824 & 39078 & 10.8 & 39078 & 11.5 & 2.80 & 2.17 & 3.50 & 2.51 & 1.39 & 44865 & 44540 \\
\hline 1 & 5035 & 1 & Torreón & 529512 & 512163 & 96.7 & 196893 & 11813 & 6.0 & 19430 & 10.0 & 3.27 & 2.20 & 3.67 & 2.54 & 1.32 & 27521 & 51974 \\
\hline 2 & 5017 & 2 & Matamoros & 92029 & 59191 & 64.9 & 30886 & 8048 & 26.1 & 1182 & 5.1 & 2.17 & -0.50 & 4.74 & 1.92 & 0.64 & 238 & 2585 \\
\hline 3 & 10007 & 2 & Gómez Palacio & 273315 & 213880 & 78.3 & 96160 & 9870 & 10.3 & 15052 & 15.9 & 2.06 & 2.60 & 2.99 & 2.66 & 1.63 & 15905 & 58192 \\
\hline 4 & 10012 & 2 & Lerdo & 112435 & 73911 & 65.7 & 36885 & 9347 & 25.3 & 3415 & 12.3 & 3.24 & 3.63 & 2.79 & 2.58 & 1.79 & 1201 & 10684 \\
\hline 9 & & & Mbrida & 865461 & 810996 & 93.7 & 340053 & 22463 & 6.6 & 22463 & 6.9 & $1.8 I$ & 2.47 & 4.95 & 3.32 & 2.45 & 23646 & 27322 \\
\hline 1 & 31050 & 1 & Mérida & 705055 & 682156 & 96.8 & 281230 & 2162 & 0.8 & 19737 & 6.9 & 1.80 & 2.50 & 5.58 & 2.82 & 2.41 & 21548 & 30562 \\
\hline 2 & 31002 & 2 & Acanceh & 13166 & 9311 & 70.7 & 4732 & 2026 & 42.8 & 394 & 11.6 & 1.91 & 2.27 & 1.36 & 3.55 & 1.57 & 51 & 3905 \\
\hline 3 & 31015 & 2 & Cuzamá & 4387 & & 0.0 & 1419 & 708 & 49.9 & 27 & 3.8 & 1.02 & 1.98 & 2.04 & 2.39 & 1.98 & 3 & 595 \\
\hline 4 & 31038 & 2 & Hunucmá & 25979 & 23628 & 91.0 & 9194 & 1604 & 17.4 & 403 & 5.3 & 1.82 & 2.36 & 4.42 & 3.06 & 1.94 & 55 & 2130 \\
\hline 5 & 31041 & 2 & Kanasin & 39191 & 37674 & 96.1 & 14399 & 6835 & 47.5 & 479 & 6.2 & 1.96 & 2.80 & $1.2 \mathrm{I}$ & 13.50 & 4.85 & 231 & 5894 \\
\hline 6 & 31067 & 2 & Seyé & 8275 & 7374 & 89.1 & 3008 & I 613 & 58.6 & 80 & 5.8 & 2.56 & 1.63 & 1.83 & -0.72 & 2.31 & 10 & 1221 \\
\hline 7 & 31076 & 2 & Tecoh & 14380 & 8189 & 56.9 & 4955 & 2233 & 45.1 & 174 & 6.6 & 1.30 & 2.15 & -0.46 & 3.44 & 1.53 & 36 & 2530 \\
\hline 8 & 31090 & 2 & Timucuy & 5883 & 3324 & 56.5 & 2111 & 608 & 28.8 & 21 & 2.7 & 2.12 & 2.34 & 0.42 & 4.77 & 2.05 & 2 & 395 \\
\hline 9 & 31101 & 2 & Umân & 49145 & 39340 & 80.0 & 19005 & 4674 & 24.6 & 1209 & 8.0 & 1.83 & 2.59 & 1.97 & 8.78 & 2.27 & 1710 & 34786 \\
\hline 10 & & & San Luis Polasi & 850828 & 807696 & 94.9 & 304923 & 20338 & 6.7 & 20338 & 7.0 & 2.23 & 3.85 & 4.56 & 3.49 & 2.61 & 48372 & 56853 \\
\hline $\mathbf{1}$ & 24028 & 1 & San Luis Potosi & 670532 & 688122 & 95.2 & 243041 & 2354 & 1.0 & 17984 & 7.2 & 2.24 & 3.42 & 4.11 & 2.66 & 2.48 & 46044 & 68668 \\
\hline 2 & 24035 & 2 & Soledad de Graciano Sánchez & 180296 & 169574 & 94.1 & 61882 & 17984 & 29.1 & 2354 & 5.6 & 2.12 & 9.06 & 7.99 & 7.70 & 3.11 & 2328 & 12911 \\
\hline
\end{tabular}




\section{CUADRO 1A (continuación)}

\begin{tabular}{|c|c|c|c|c|c|c|c|c|c|c|c|c|c|c|c|c|c|c|}
\hline & & & & & arócter urba & & & Inlegración & funcion & & & & Dinán & rica demo & grafica & & Importancia ec & económica \\
\hline & & & & & Población & Crado & & & & & & & & & & & VBP total & $V B P$ \\
\hline & & & & Población & urbana & de urbar & PEA & VPT O & rigen &.$- V P T d$ & tina & & as de or & ramiento & intercens & & 1998 (millo p & per cripita \\
\hline$N u \dot{m}$ & m. Clave & & bo Nombre & 2000 & 2000 & nizacion & total & Total & $\%$ & Total & $\%$ & $50-60$ & 6070 & 70.80 & $80-90$ & $90-00$ & nes de pesas) & (pesas) \\
\hline II & & & Quenttoro & 836895 & 709382 & 84.8 & 301180 & 12757 & 4.2 & 12757 & 4.5 & 2.75 & 4.27 & 5.42 & 4.34 & 3.49 & 50818 & 60722 \\
\hline 1 & 22014 & 1 & Querétaro & 641386 & 594513 & 92.7 & 239674 & 2243 & 0.9 & 8488 & 8.6 & 2.82 & 4.79 & 5.85 & 4.62 & 3.49 & 40743 & 63523 \\
\hline 2 & 22006 & 2 & Corregidora & 74558 & 58843 & 78.9 & 25581 & 4637 & 18.1 & 782 & 4.1 & 3.50 & 2.27 & 5.56 & 4.05 & 5.51 & 2590 & 34739 \\
\hline 3 & 22011 & 2 & Marqués, El & 71397 & 27207 & 38.1 & 20929 & 3320 & 15.9 & 2615 & 18.8 & 2.19 & 3.25 & 3.83 & 3.32 & 2.62 & 5108 & 71542 \\
\hline 4 & 22012 & 2 & Pedro Escobedo & 49554 & 28819 & 58.2 & 14996 & 2557 & 17.1 & 872 & 7.9 & 2.40 & 3.61 & 3.71 & 3.08 & 2.26 & 2377 & 47964 \\
\hline 12 & & & Aguascalientes & 761878 & 673015 & 88.3 & 274689 & 11270 & 4.1 & 11270 & 4.3 & 2.61 & 4.53 & 4.57 & 3.64 & 2.90 & 35460 & 46543 \\
\hline 1 & 1001 & 1 & Aguascalientes & 643419 & 601228 & 93.4 & 236234 & 3473 & 1.5 & 5796 & 2.5 & 2.67 & 3.97 & 4.65 & 3.57 & 2.44 & 26777 & 41617 \\
\hline 2 & 1005 & 2 & Jesús María & 64097 & 36995 & 57.7 & 21647 & 4096 & 18.9 & 2868 & 15.1 & 1.81 & 3.48 & 4.05 & 5.15 & 4.58 & 7261 & 119283 \\
\hline 3 & 1006 & 2 & Pabellón de Arteaga & 34296 & 24195 & 70.5 & 10840 & 2395 & 22.1 & 667 & 8.4 & & & 3.76 & 2.83 & 2.81 & 218 & 6352 \\
\hline 4 & 1011 & 25 & San Francisco de los Romo & 20066 & 10597 & 52.8 & 5968 & 1906 & 21.9 & 1939 & 80.3 & & & & & & 1204 & 60009 \\
\hline 13 & & & Cuernavaca & 759554 & 718110 & 94.5 & 277687 & 47314 & 17.0 & 47.314 & 18.3 & 4.36 & 6.56 & 5.30 & 2.92 & 3.20 & 27373 & 36038 \\
\hline 1 & 17007 & 1 & Cuernavaca & 338706 & 330689 & 97.6 & 132257 & 6049 & 4.6 & 33666 & 22.1 & 4.54 & 6.76 & 8.62 & 1.98 & 1.89 & $8 \$ 42$ & 24628 \\
\hline 2 & 17008 & 2 & Emiliano Zapata & 57617 & 50499 & 87.6 & 19400 & 8438 & 43.5 & 1607 & 14.6 & 1.46 & 7.66 & 6.75 & 4.95 & 5.57 & 956 & 16585 \\
\hline 3 & 17011 & 2 & Jiutepec & 170589 & 166494 & 97.6 & 62729 & 15870 & 25.3 & 7181 & 14.2 & 7.50 & 9.10 & 13.06 & 3.90 & 5.39 & 17390 & 101589 \\
\hline 4 & 17017 & 21 & Puente de Ixcla & 54149 & 47317 & 87.4 & 17295 & 3221 & 18.6 & 247 & 2.1 & 2.84 & 8.93 & 8.58 & 2.41 & 2.18 & 221 & 4079 \\
\hline 5 & 17018 & 2 & Temixco & 92850 & 85914 & 92.5 & 31278 & 9093 & 29.1 & 3255 & 14.1 & 5.66 & 8.32 & 8.69 & 4.24 & 3.23 & 290 & 3127 \\
\hline 6 & 17028 & 27 & Xochitepec & 4564.3 & 37257 & 81.6 & 14728 & 4643 & 31.5 & 1358 & 18.1 & 4.04 & 3.28 & 3.56 & 5.55 & 5.11 & 285 & 5144 \\
\hline 14 & & & Villahermosa & 669326 & 453997 & 67.8 & 233071 & 11476 & 4.9 & 11476 & 5.2 & 3.24 & 4.14 & 3.91 & 4.56 & 3.09 & 24314 & 36326 \\
\hline 1 & 27004 & 1 & Centro & 520308 & 404627 & 77.8 & 188446 & 455 & 0.2 & 10226 & 5.4 & 3.35 & 4.72 & 4.22 & 4.53 & 3.03 & 24128 & 46372 \\
\hline 2 & 27010 & $2 \mathrm{~J}$ & Jalpa de Méndez & 68746 & 21346 & 31.1 & 18852 & 3317 & 17.6 & 372 & 2.7 & 3.30 & 8.07 & 2.73 & 3.90 & 1.86 & 109 & 1589 \\
\hline 3 & 27013 & 21 & Nacajuca & 80272 & 28024 & $\$ 4.9$ & 25778 & 7704 & 29.9 & 878 & 5.1 & 2.59 & 1.74 & 8.07 & 5.60 & 4.72 & 77 & 955 \\
\hline 15 & & & Tampico & 655760 & 622900 & 95.0 & 238624 & 47627 & 20.0 & 47627 & 21.0 & 2.82 & 4.57 & 3.53 & 1.84 & 1.59 & 27238 & 41536 \\
\hline 1 & 28038 & 17 & Tampico & 295442 & 295442 & 100.0 & 112749 & 14150 & 12.6 & 26178 & 21.9 & 2.61 & 4.16 & 3.64 & 0.18 & 0.81 & 7131 & 24136 \\
\hline 2 & 28008 & 2 & Altamira & 127664 & 99817 & 78.2 & 42812 & 9571 & 22.4 & 10878 & 25.4 & 5.08 & 3.68 & 2.12 & 8.72 & 4.49 & $10 \$ 17$ & 80818 \\
\hline 3 & 28009 & 2 & Giudad Madero & 182325 & 182325 & 100.0 & 66459 & 17265 & 26.0 & 9787 & 17.7 & 2.70 & 5.64 & 3.67 & 1.98 & 1.30 & 9324 & 51137 \\
\hline 4 & 90133 & 21 & Pueblo Viejo & 50329 & 45316 & 90.0 & 16604 & 6641 & 40.0 & 784 & 8.4 & 2.20 & 5.05 & 8.79 & 3.49 & 1.07 & 466 & 9262 \\
\hline
\end{tabular}




\begin{tabular}{|c|c|c|c|}
\hline 16 & & & Saltillo \\
\hline 1 & 5030 & $\mathbf{1}$ & Saltilio \\
\hline 2 & 5004 & 2 & Arteaga \\
\hline 3 & 5027 & 2 & Ramos Arizpe \\
\hline 17 & & & Veracriaz \\
\hline 1 & $\$ 0193$ & I & Veracruz \\
\hline 2 & 30028 & 2 & Bóca del Río \\
\hline 18 & & & Celcrya \\
\hline 1 & 11007 & 1 & Celaya \\
\hline 2 & $\lfloor 1005$ & 2 & Apaseo el Grande \\
\hline 3 & 11011 & 2 & Cortazar \\
\hline 4 & 11044 & 2 & Villagrán \\
\hline 19 & & & Xalapa \\
\hline 1 & 30087 & 1 & Xalapa \\
\hline 2 & $\$ 0026$ & 2 & Banderilla \\
\hline 3 & 30038 & 2 & Coatepec \\
\hline 4 & 30065 & 2 & Emiliano Zapata \\
\hline 5 & 30136 & 2 & Rafael Lucio \\
\hline 6 & 30182 & 2 & Tlalnelhuayocan \\
\hline 20 & & & Rgnasa \\
\hline 1 & 28032 & 1 & Reynosa \\
\hline 2 & 28093 & 2 & Rio Bravo \\
\hline 21 & & & Tuxila Gutièrrez \\
\hline 1 & 7012 & 2 & Berriozábal \\
\hline 2 & 7027 & 2 & Chiapa de Corzo \\
\hline 3 & 7101 & 1 & Tuxula Gutiérrez \\
\hline 22 & & & Oaxaca \\
\hline 1 & 20067 & 1 & Oaxaca de Juárez \\
\hline 2 & 20023 & 2 & Cuiläpam de Guerrero \\
\hline 3 & 20033 & 2 & Guadalupe Eua \\
\hline 4 & 20089 & 2 & San Agustín de las Juntas \\
\hline 5 & 20087 & 2 & San Agustin Yacareni \\
\hline
\end{tabular}

\begin{tabular}{|c|c|c|c|c|c|c|c|c|c|c|c|c|c|c|}
\hline 637273 & 599951 & 94.1 & 227656 & 15347 & 6.7 & 15347 & 6.9 & 1.81 & 3.77 & 4.69 & 3.04 & 2.76 & 69207 & 108599 \\
\hline 578046 & 562587 & 97.3 & 208400 & 13145 & 6.3 & 1858 & 1.0 & 2.62 & 4.26 & 5.17 & 3.28 & 2.77 & 44626 & 77201 \\
\hline 19374 & 6042 & 31.2 & 5534 & 946 & 17.1 & 1045 & 18.9 & -0.47 & 1.85 & 1.48 & -0.53 & 1.08 & 557 & 28737 \\
\hline 39853 & 31322 & 78.6 & 13722 & 1256 & 9.2 & 12444 & 50.5 & -1.85 & 1.18 & 1.77 & 2.08 & 8.53 & 24025 & 602839 \\
\hline 593181 & 574235 & 96.8 & 227043 & 14615 & 6.4 & 14615 & 6.8 & 3.77 & 4.88 & 3.66 & 2.62 & 2,30 & 20823 & 35104 \\
\hline 457377 & 439481 & 96.1 & 175270 & 6266 & 3.6 & 8349 & 5.0 & 3.64 & 4.28 & 2.77 & 0.75 & 3.39 & 18982 & 41502 \\
\hline 135804 & 134754 & 99.2 & 51773 & 8949 & 16.1 & 6266 & 13.7 & 7.51 & 14.53 & 10.05 & 9.07 & -0.63 & 1841 & 13556 \\
\hline 578996 & 416308 & 71.9 & 189829 & 10652 & 5.6 & 10652 & 5.9 & 3.87 & 3.90 & 3.52 & 3.21 & 1.80 & 21075 & 36399 \\
\hline 382958 & 300291 & 78.4 & 132081 & 1716 & 1.8 & 7413 & 5.6 & 4.67 & 4.26 & 3.91 & 3.64 & 2.18 & 15351 & 40087 \\
\hline 68738 & 29592 & 43.1 & 19039 & 2380 & 12.5 & 685 & 4.2 & 1.41 & 3.46 & 2.76 & 3.34 & 1.11 & 2452 & 35665 \\
\hline 81359 & 53886 & 66.2 & 25411 & 3710 & 14.6 & 1224 & 5.7 & 3.74 & 3.21 & 2.91 & 2.00 & 0.91 & 1277 & 15692 \\
\hline 45941 & 32539 & 70.8 & 13298 & 2846 & 21.4 & 1330 & 11.9 & 3.75 & 9.70 & 3.21 & 2.22 & 1.75 & 1995 & 49425 \\
\hline 541965 & 453551 & 83.7 & 215326 & 16531 & 7.7 & 16531 & 8.1 & 2.51 & 4.16 & 4.45 & 3.12 & 2.60 & 7577 & 13980 \\
\hline 390590 & 379246 & 97.1 & 156410 & 2773 & 1.8 & 13275 & 8.3 & 2.80 & 5.46 & 4.85 & 3.16 & 3.10 & 4599 & 11778 \\
\hline 16433 & 15422 & 93.8 & 5963 & 2248 & 37.7 & 595 & 15.3 & 2.38 & 1.05 & 6.80 & 10.95 & -2.95 & 82 & 4995 \\
\hline 73536 & 45339 & 61.7 & 30176 & 3782 & 12.5 & 1840 & 6.8 & 1.98 & 1.65 & 3.36 & 2.06 & 1.77 & 2618 & 35602 \\
\hline 44580 & 6545 & 14.7 & 17127 & 4765 & 27.8 & 629 & 5.3 & 2.56 & 2.99 & 3.44 & 1.46 & 2.07 & 264 & 5924 \\
\hline 5342 & 3050 & 57.1 & 1879 & 880 & 46.9 & 106 & 10.5 & 2.16 & 2.86 & 4.11 & 1.73 & 2.19 & 3 & 544 \\
\hline 11484 & 3949 & 34.4 & 3771 & 2082 & 55.2 & 85 & 5.3 & 0.74 & 1.69 & 3.65 & 4.35 & 5.17 & 11 & 977 \\
\hline 524692 & 492299 & 93.8 & 196871 & 4957 & 2.5 & 4957 & 2.6 & 6.86 & 5.31 & 2.77 & 2.54 & 3.40 & 15648 & 29824 \\
\hline 420463 & 403718 & 96.0 & 161499 & 323 & 0.2 & 4684 & 2.9 & 6.86 & 1.16 & 3.32 & 3.02 & 4.08 & 14293 & 33993 \\
\hline 104229 & 88581 & 85.0 & 35372 & 4634 & 13.1 & 329 & 1.1 & & & 1.53 & 1.22 & 1.05 & 1356 & 13007 \\
\hline 523482 & 480919 & 91.9 & 188296 & 6268 & 3.3 & 6268 & 3.5 & 2.45 & 4.26 & 7.05 & 5.54 & 3.76 & 6693 & 12786 \\
\hline 28719 & 19328 & 67.3 & 9213 & 2387 & 25.9 & 275 & 4.1 & 1.97 & 2.69 & 6.37 & 2.41 & 2.64 & 72 & 2506 \\
\hline 60620 & 29341 & 48.4 & 18781 & 2794 & 14.9 & 841 & 5.3 & 0.07 & 3.34 & 1.63 & 4.16 & 3.01 & 767 & 12650 \\
\hline 434143 & 432250 & 99.6 & 160302 & 1087 & 0.7 & 5152 & 3.3 & 3.74 & 4.85 & 8.58 & 6.05 & 3.95 & 5854 & 13485 \\
\hline 517683 & 464529 & 89.7 & 196385 & 41515 & 21.1 & 41515 & 22.6 & 3.40 & 3.42 & 3.17 & 4.38 & 3.37 & 6561 & 12674 \\
\hline 256130 & 254515 & 99.4 & 100228 & 3657 & 3.6 & 31981 & 26.1 & 4.64 & 4.15 & 2.95 & 3.20 & 1.83 & 4582 & 17888 \\
\hline 12812 & & 0.0 & 3966 & 1029 & 25.9 & 60 & 2.4 & 1.99 & 2.05 & 4.87 & -0.84 & 2.73 & 8 & 609 \\
\hline 2004 & & 0.0 & 690 & 208 & 30.2 & 162 & 27.6 & 0.12 & 0.96 & 3.24 & $0 . \overline{5} 8$ & 1.25 & 238 & 118781 \\
\hline 4970 & 4668 & 93.9 & 1790 & 681 & 98.0 & 393 & 25.8 & 2.94 & 3.39 & 3.78 & 5.56 & 6.56 & 181 & 36325 \\
\hline 3400 & 2974 & 87.5 & 1174 & 125 & 10.6 & 809 & 23.0 & 2.52 & 3.88 & 2.12 & 2.49 & 2.40 & 11 & 3294 \\
\hline
\end{tabular}




\section{CUADRO 1A (continuación)}

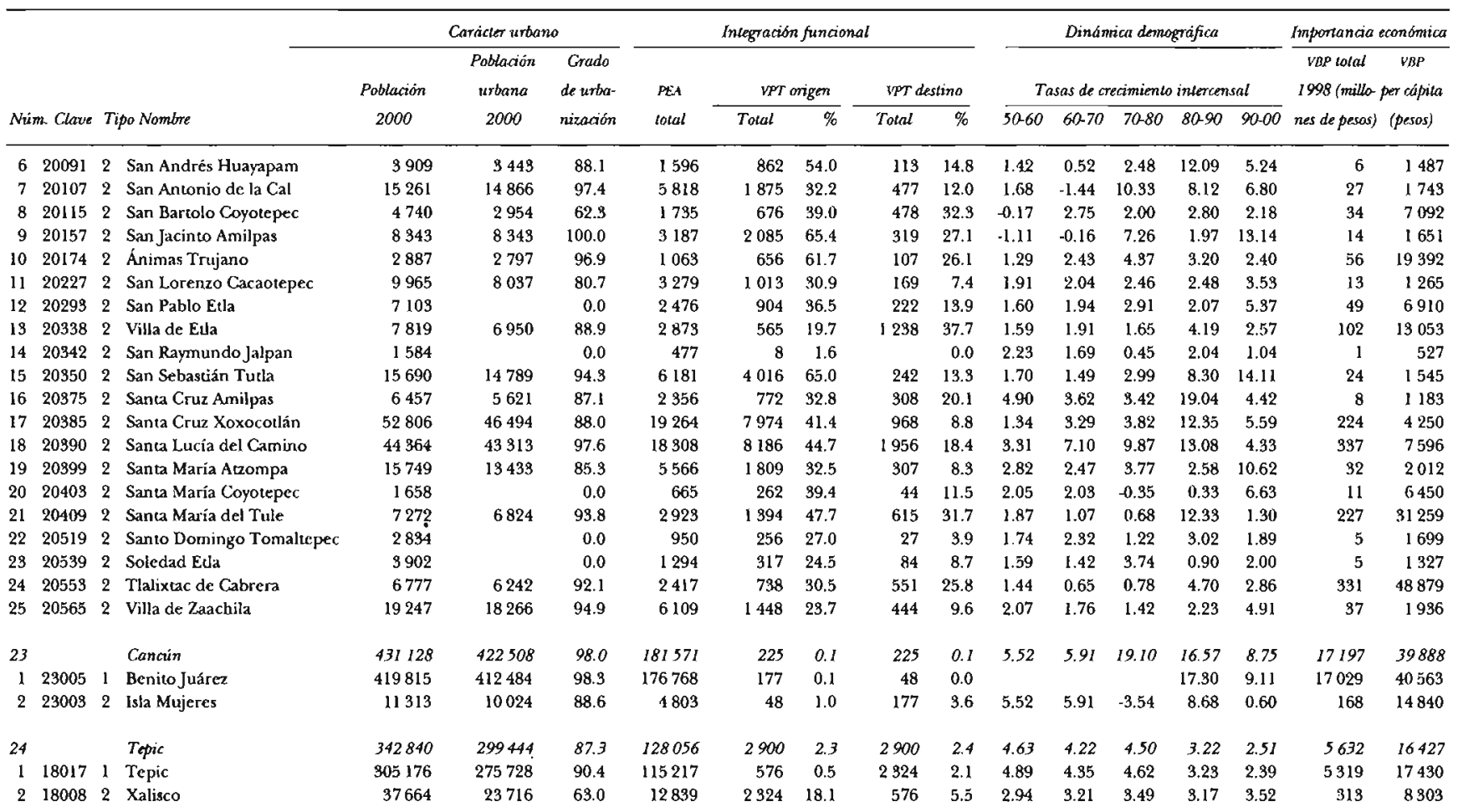




\begin{tabular}{|c|c|c|c|c|c|c|c|c|c|c|c|c|c|c|c|c|c|c|}
\hline 25 & & & Contzocoalcos & 307724 & 295283 & 96.0 & 108150 & 5026 & 4.6 & 5026 & 4.9 & 6.78 & 6.75 & 5.18 & 2.79 & 1.26 & 34137 & 110933 \\
\hline 1 & 30039 & 1 & Coalzacoalcos & 267212 & 260405 & 97.5 & 95762 & 862 & 0.9 & 3406 & 3.6 & 6.74 & 7.53 & 5.25 & 2.33 & 1.98 & 33582 & 125677 \\
\hline 2 & 30082 & 2 & Ixhuatlán del Sureste & 13294 & 8969 & 67.5 & 3747 & 1476 & 39.4 & 9 & 0.4 & 7.01 & 2.05 & 4.55 & -5.86 & 1.05 & 471 & 35458 \\
\hline 3 & 30206 & 2 & Nanchital de L. Cárdenas del Río & o 27218 & 25909 & 95.2 & 8641 & 2688 & 31.1 & 1611 & 22.8 & & & & & 0.19 & 83 & 3051 \\
\hline 26 & & & Monclova & 302899 & 296293 & 97.8 & 99221 & 12703 & 12.8 & 12703 & 13.1 & 4.98 & 5.53 & 3.09 & 4.36 & 0.74 & 25554 & 84365 \\
\hline 1 & 5018 & 1 & Monclova & 198744 & 192554 & 99.4 & 65277 & 4495 & 6.9 & 7294 & 11.0 & 7.71 & 6.34 & 3.73 & 4.19 & 0.82 & 21312 & 110003 \\
\hline 2 & 5006 & 2 & Castaños & 22530 & 19794 & 87.9 & 6471 & 2059 & 31.8 & 772 & 15.8 & 0.91 & 4.01 & 1.36 & 3.21 & 0.54 & 467 & 20728 \\
\hline 3 & 5010 & 2 & Frontera & 66579 & 66041 & 99.2 & 20780 & 4456 & 21.4 & 4404 & 21.6 & 3.92 & 5.77 & 2.24 & 5.88 & 0.81 & 3709 & 55715 \\
\hline 4 & 5031 & 2 & San Buenaventura & 20046 & 17904 & 89.3 & 6699 & 1693 & 25.8 & 233 & 4.7 & 1.45 & 2.17 & 2.29 & 2.97 & -0.09 & 65 & 3256 \\
\hline 27 & & & Pachuca & 287431 & 267293 & 93.0 & 111922 & 3624 & 3.2 & 3624 & 3.6 & 0.97 & 2.51 & 3.79 & 3.62 & 3.65 & 5285 & 18385 \\
\hline 1 & 13048 & 1 & Pachuca de Soto & 245208 & 234329 & 95.6 & 96261 & 379 & 0.4 & 3245 & 3.7 & 1.14 & 2.51 & 3.84 & 3.01 & 3.13 & 3814 & 15554 \\
\hline 2 & 13051 & 2 & Mineral de la Reforma & 42223 & 32964 & 78.1 & 15661 & 3245 & 20.7 & 379 & 3.2 & -1.59 & 2.41 & 2.90 & 11.57 & 7.98 & I 471 & 34892 \\
\hline 28 & & & Minatillän & 285625 & 216981 & 76.0 & 88894 & 17996 & 20.2 & 17996 & 23.1 & 3.82 & 3.88 & 4.84 & 2.63 & 0.47 & 18265 & 63948 \\
\hline 1 & 30108 & 1 & Minatitän & 153001 & 112150 & 73.3 & 48431 & 1792 & 3.7 & 15726 & 27.2 & 4.41 & 3.44 & 4.23 & 3.09 & -2.44 & 13284 & 86824 \\
\hline 2 & 30048 & 2 & Cosoleacaque & 97437 & 77688 & 79.7 & 30465 & 13554 & 44.5 & 2059 & 14.9 & 2.36 & 6.94 & 7.59 & 0.67 & 7.68 & 4545 & 46644 \\
\hline 3 & 30059 & 2 & Chinameca & 14105 & 6943 & 49.2 & 4328 & 610 & 14.1 & 177 & 5.3 & 2.04 & 4.65 & 4.07 & 1.50 & 0.77 & 402 & 28535 \\
\hline 4 & 30120 & 2 & Oteapan & 12137 & 12115 & 99.8 & 3397 & 1128 & 33.2 & 34 & 2.2 & 2.44 & 1.93 & 4.45 & 5.70 & 1.29 & 28 & 2288 \\
\hline 5 & 30199 & 2 & Zaragoza & 8945 & 8085 & 90.4 & 2273 & 912 & 40.1 & & 0.0 & 1.41 & 1.66 & 4.65 & 3.07 & 2.92 & 6 & 648 \\
\hline 29 & & & Orizaba & 282093 & 223206 & 79.1 & 101008 & 19054 & 18.9 & 19054 & 20.9 & 2.40 & 2.86 & 2.73 & 0.65 & 1.28 & 10956 & 38840 \\
\hline 1 & 30118 & 1 & Orizaba & 118593 & 118552 & 100.0 & 43576 & 3527 & 8.1 & 12869 & 26.2 & 2.30 & 2.98 & 2.11 & -0.06 & 0.38 & 5987 & 50486 \\
\hline 2 & 30074 & 2 & Huiloapan & 5733 & 3700 & 64.5 & 1922 & 794 & 41.3 & 100 & 9.5 & 2.57 & 3.82 & 3.29 & 1.81 & 1.89 & 42 & 7279 \\
\hline 3 & 30081 & 2 & lxhuaclancillo & 11914 & 9966 & 83.6 & 4290 & 1231 & 28.7 & 142 & 5.5 & -0.05 & -0.13 & 1.19 & 5.45 & 6.21 & 27 & 2252 \\
\hline 4 & 30085 & 2 & Ixtaczoquitlán & 56896 & 23022 & 40.5 & 20819 & 3653 & 17.5 & 2669 & 14.6 & 2.00 & 3.05 & 3.36 & 3.17 & 2.68 & 4571 & 80337 \\
\hline 5 & 30115 & 2 & Nogales & 30945 & 20530 & 66.3 & 10208 & 2617 & 25.6 & 775 & 12.0 & 1.97 & 2.89 & 4.64 & -1.25 & 1.19 & 122 & 3927 \\
\hline 6 & $\mathbf{3 0 1 3 5}$ & 2 & Rafael Delgado & 14730 & 5443 & 37.0 & 4922 & 1836 & 37.3 & 121 & 4.2 & 2.48 & 4.61 & 3.34 & 1.75 & 2.88 & 10 & 696 \\
\hline 7 & 30138 & 2 & Rio Blanco & 39327 & 39286 & 99.9 & 14052 & 4943 & 35.2 & $2 \$ 46$ & 28.5 & 4.44 & 2.26 & 2.65 & 0.55 & 0.43 & 186 & 4730 \\
\hline 8 & 30185 & 2 & Ttilapan & 3955 & 2707 & 68.4 & 1219 & 451 & 37.0 & 31 & 4.4 & 1.64 & 2.51 & 4.06 & 3.21 & 2.42 & 12 & 3035 \\
\hline 30 & & & Tehruacín & 278577 & 235213 & 84.4 & 106079 & 5245 & 4.9 & 5245 & 5.2 & 2.71 & 4.03 & 4.60 & 3.13 & 3.69 & 7440 & 26707 \\
\hline 1 & 21156 & 1 & Tehuacán & 226258 & 204598 & 90.4 & 88078 & 528 & 0.6 & 4666 & 5.2 & 2.98 & 4.39 & 4.99 & 3.32 & 3.85 & 6671 & 29482 \\
\hline 2 & 21013 & 2 & Altepexi & 15811 & 15247 & 96.4 & 6208 & 968 & 15.6 & 98 & 2.4 & 1.46 & 3.76 & 3.93 & 2.22 & 2.55 & 36 & 2296 \\
\hline 3 & 21046 & 2 & Chapulco & 5542 & 4099 & 72.9 & 1753 & 624 & 35.6 & 3 & 0.3 & 2.44 & 3.29 & 1.42 & 3.46 & 2.68 & 29 & 5157 \\
\hline 4 & 21149 & 2 & Santiago Miahuatlán & 14249 & 11329 & 79.5 & 5016 & 2170 & 43.3 & 203 & 6.9 & 0.73 & 2.89 & 2.91 & 2.62 & 4.65 & 269 & 18908 \\
\hline 5 & 21161 & 2 & Tepanco de López & 16717 & & 0.0 & 5029 & 955 & 19.0 & 275 & 6.6 & 3.33 & 2.85 & 3.53 & 2.10 & 2.46 & 435 & 26025 \\
\hline
\end{tabular}




\section{CUADRO 1A (continuación)}

\begin{tabular}{|c|c|c|c|c|c|c|c|c|c|c|c|c|c|c|c|c|c|c|}
\hline \multirow[b]{3}{*}{ Nüm } & \multirow[b]{3}{*}{ n. Clave } & \multirow{3}{*}{\multicolumn{2}{|c|}{ Tipo Nombre }} & \multicolumn{3}{|c|}{ Carácter urbano } & \multicolumn{5}{|c|}{ Integracion fincional } & \multicolumn{5}{|c|}{ Dinámica demografica } & \multicolumn{2}{|c|}{ Imponancia económico } \\
\hline & & & & \multirow{2}{*}{$\begin{array}{c}\text { Población } \\
2000\end{array}$} & \multirow{2}{*}{$\begin{array}{c}\text { Población } \\
\text { urbana } \\
2000\end{array}$} & \multirow{2}{*}{$\begin{array}{l}\text { Grado } \\
\text { de urba- } \\
\text { nización }\end{array}$} & \multirow{2}{*}{$\begin{array}{l}\text { PES } \\
\text { total }\end{array}$} & \multicolumn{2}{|c|}{ YPT origen } & \multicolumn{2}{|c|}{ VPT destino } & \multicolumn{5}{|c|}{ Tasas de crecimiento intercensal } & \multirow{2}{*}{$\begin{array}{c}\text { VBP total } \\
1998 \text { (millo } \\
\text { nes de pesos) }\end{array}$} & \multirow{2}{*}{$\begin{array}{c}\text { VBP } \\
\text { per ctipita } \\
\text { (pesos) }\end{array}$} \\
\hline & & & & & & & & Total & $\%$ & Total & $\not 0$ & $50-60$ & $60-70$ & $70-80$ & $80-90$ & 9000 & & \\
\hline 31 & & & Tlaxcala & 267308 & 225316 & 84.3 & 93336 & 15394 & 16.5 & 15394 & 20.3 & 2.34 & 2.45 & 2.90 & 3.68 & 2.55 & 5214 & 19506 \\
\hline 1 & 29038 & 1 & Tlaxcala & 79280 & 73218 & 100.0 & 27352 & 2267 & 8.3 & 5530 & 21.4 & 2.78 & 3.14 & 4.79 & 3.71 & 3.82 & 1297 & 17717 \\
\hline 2 & 29001 & 2 & Amaxac de Guerrero & 7679 & 7107 & 92.6 & 2580 & 611 & 23.7 & 200 & 15.8 & 1.33 & 4.57 & -0.23 & 2.81 & 2.19 & 11 & 1472 \\
\hline 3 & 29002 & 2 & Apetatitán de Antonio Carvajal & 11795 & 6476 & 54.9 & 4105 & 928 & 22.6 & 1118 & 33,8 & 1.60 & -0.46 & 4.88 & 4.10 & 2.77 & 197 & 11640 \\
\hline 4 & 29010 & 2 & Chiautempan & 57512 & 50505 & 87.8 & 20275 & 3207 & 15.8 & 4369 & 23.2 & 3.00 & 2.64 & 2.37 & 4.05 & -0.62 & 985 & 16253 \\
\hline 5 & 29018 & 2 & Conda de Juan Cuamatzi & 28842 & 22646 & 78.5 & 10431 & 1808 & 17.3 & 973 & 11.6 & 2.61 & 2.44 & 3.54 & 2.81 & 2.59 & 145 & 5026 \\
\hline 6 & 29024 & 2 & Panotla & 23391 & 13575 & 58.0 & 8451 & 1562 & 18.5 & 328 & 6.9 & 1.89 & 1.91 & 1.84 & 2.73 & 2.73 & 24 & 1005 \\
\hline 7 & 29026 & 2 & Santa Cruz Tlaxcala & 12824 & 8282 & 64.6 & 4439 & 1361 & 30,7 & 214 & 10.0 & 0.80 & 0.97 & 2.56 & 2.96 & 2.01 & 40 & 3135 \\
\hline 8 & 29028 & 2 & Teolocholco & 17067 & 14462 & 84.7 & 5346 & 901 & 16.9 & 925 & 22.6 & 2.26 & 2.50 & 1.47 & 4.94 & 2.24 & 1606 & 94079 \\
\hline 9 & 29029 & 2 & Tepeyanco & 9006 & 3106 & 34.5 & 2750 & 508 & 18.5 & 109 & 6.1 & 1.70 & 2.31 & 2.13 & 4.22 & -6.17 & 3 & 290 \\
\hline 10 & 29048 & 2 & Magdalena Tlaltelulco, La & 13697 & 13697 & 100.0 & 4362 & 1484 & 34.0 & 587 & 22.9 & & & & & & 698 & 50596 \\
\hline 11 & 29050 & 2 & San Francisco Tetlanohcan & 9081 & 9068 & 99.8 & 2924 & 643 & 27.6 & 176 & 12.4 & & & & & & 16 & 1753 \\
\hline 12 & 29060 & 2 & Santa Isabel Xiloxoxtla & 3184 & 3184 & 100.0 & 927 & 115 & 12.4 & 864 & 61.8 & & & & & & 307 & 96527 \\
\hline 32 & & & Zacalecas & 246045 & 215566 & 87.6 & 83026 & 8892 & 10.7 & 8892 & 12.2 & 2.46 & 4.01 & 4.32 & 3.24 & 2.57 & 2486 & 10103 \\
\hline 1 & 32056 & 1 & Zacatecas & 123890 & 113947 & 92.0 & 44976 & 3116 & 6.9 & 5616 & 13.7 & 2.40 & 4.46 & 4.15 & 2.08 & 1.34 & 1703 & 18748 \\
\hline 2 & 92017 & 2 & Guadalupe & 109066 & 91236 & 83.7 & 35022 & 5237 & 15.0 & 3276 & 10.9 & 2.56 & 3.26 & 4.64 & 5.01 & 2.82 & 783 & 7175 \\
\hline 3 & 32057 & 2 & Trancoso & 13080 & 10383 & 79.4 & 3028 & 539 & 17.8 & & 0.0 & & & & & & & \\
\hline 33 & & & Puerto Vallarta & 244536 & 205898 & 84.2 & 96570 & 2670 & 2.8 & 2670 & 2.9 & 3.65 & 9.13 & 4.57 & 10.50 & 4.96 & 8172 & 33417 \\
\hline 1 & 14067 & 1 & Puerto Vallaria & 184728 & 175164 & 94.8 & 73965 & 296 & 0.4 & 2374 & 3.2 & 3.65 & 9.13 & 4.57 & 7.10 & 5.22 & 7346 & 39767 \\
\hline 2 & 18020 & 2 & Bahía de Banderas & 59808 & 30734 & 51.4 & 22605 & 2374 & 10.5 & 296 & 1.6 & & & & & 4.18 & 826 & 18804 \\
\hline 34 & & & San Juan del Rio & 229637 & 161304 & 70.2 & 82294 & 3452 & 4.2 & 3452 & 4.4 & 2.35 & 3.25 & 4.09 & 4.31 & 3.36 & 17890 & 77906 \\
\hline 1 & 22016 & 1 & San Juan del Río & 179668 & 128716 & 71.6 & 64760 & 335 & 0.5 & 8117 & 4.8 & 2.36 & 3.29 & 4.12 & 4.57 & 3.59 & 17514 & 97480 \\
\hline 2 & 22017 & 2 & Tequisquiapan & 49969 & 32588 & 65.2 & 17534 & 3117 & 17.8 & 335 & 2.3 & 2.33 & 3.12 & 4.02 & 3.50 & 2.59 & 376 & 7525 \\
\hline 35 & & & Córdoba & 223341 & 180955 & 81.0 & 85990 & 3728 & 4.3 & 3728 & 4.7 & 2.31 & 4.29 & 3.00 & 1.89 & 1.79 & 6726 & 30115 \\
\hline 1 & 30044 & 1 & Córdoba & 177288 & 150821 & 85.1 & 67991 & 864 & 1.3 & 2864 & 4.4 & 2.31 & 4.26 & 2.96 & 1.82 & 1.67 & 5745 & 32404 \\
\hline 2 & 30068 & 2 & Fortín & 46058 & 30194 & 65.4 & $17999^{\circ}$ & 2864 & 15.9 & 864 & 6.0 & 2.35 & 4.41 & 3.16 & 2.17 & 2.26 & 981 & 21306 \\
\hline
\end{tabular}




\begin{tabular}{|c|c|c|c|c|c|c|c|c|c|c|c|c|c|c|c|c|c|c|}
\hline 36 & & & Cuautla & 222710 & 168102 & 75.5 & 77552 & 4928 & 6.4 & 4928 & 7.0 & 3.50 & 5.36 & 3.40 & 2.41 & 2.56 & 4365 & 19601 \\
\hline 1 & 17006 & 1 & Cuautia & 153329 & 140617 & 91.7 & 55925 & 1230 & 2.2 & 3698 & 7.0 & 8.57 & 5.13 & 8.04 & 2.55 & 2.47 & 2371 & 15461 \\
\hline 2 & 17004 & 2 & Ayala & 69381 & 27485 & 39.6 & 21627 & 3698 & 17.1 & 1230 & 7.1 & $\cdot 3.33$ & 5.94 & 4.24 & 2.11 & 2.76 & 1995 & 28750 \\
\hline 37 & & & Zamora & 216048 & 171078 & 79.2 & 74572 & 3157 & 4.2 & 3157 & 4.3 & 3.76 & 4.98 & 3.05 & 2.28 & 1.55 & 4212 & 1949 \\
\hline 1 & 16108 & 1 & Zamora & 161918 & 122881 & 75.9 & 56032 & 728 & 1.3 & 2429 & 4.3 & 3.66 & 4.56 & 3.07 & 2.53 & 1.13 & 2687 & 16597 \\
\hline 2 & 16043 & 2 & Jacona & 54180 & 48197 & 89.0 & 18540 & 2429 & 13.1 & 728 & 4.5 & 4.14 & 6.47 & 2.95 & 1.44 & 2.95 & 1525 & 28165 \\
\hline 38 & & & Colima & 210766 & 196318 & 93.1 & 80828 & 12696 & 15.7 & 12696 & 17.4 & 3.66 & 3.56 & 3.49 & 2.61 & 3.19 & 2598 & 1232 \\
\hline I & 6002 & 1 & Colima & 129958 & 119659 & 92.1 & 49998 & 1770 & 3.5 & 10926 & 19.7 & 3.85 & 3.22 & 3.13 & 1.53 & 1.11 & 2225 & 17121 \\
\hline 2 & 6010 & 2 & Villa de Álvarez & 80808 & 76679 & 94.9 & 30830 & 10926 & 35.4 & 1770 & 10.2 & 2.17 & 6.14 & 5.60 & 7.00 & 7.94 & 973 & 4610 \\
\hline 39 & & & Poza Rica & 192027 & 177444 & 92.4 & 67532 & 4420 & 6.5 & 4420 & 7.0 & 9.51 & 5.60 & 3.19 & -0.68 & 0.32 & 5604 & 2918 \\
\hline 1 & 30131 & 1 & Poza Rica de Hidalgo & 152838 & 151441 & 99.1 & 54725 & $\$ 06$ & 0.6 & 4114 & 7.5 & & 5.52 & 3.19 & -0.96 & 0.07 & 5568 & 36428 \\
\hline 2 & 90040 & 2 & Coatzinda & 39189 & 26008 & 66.4 & 12807 & 4114 & 32.1 & 306 & 3.7 & -9.11 & 6.06 & 3.17 & 0.67 & 1.38 & 37 & 939 \\
\hline 40 & & & Guaymas & 180316 & 136126 & 75.5 & 63532 & 3430 & 5.4 & 3430 & 5.5 & 6.18 & 4.91 & 1.36 & 2.39 & 0.30 & 3217 & 17840 \\
\hline 1 & 26029 & 1 & Guaymas & 130329 & 97593 & 74.9 & 46213 & 1802 & 3.9 & 1628 & 3.6 & 2.53 & 5.11 & 1.17 & 2.86 & 0.10 & 2481 & 19096 \\
\hline 2 & 26025 & 2 & Empalme & 49987 & 38533 & 77.1 & 17319 & 1628 & 9.4 & I 802 & 10.5 & 4.43 & 1.80 & 1.17 & 0.84 & 786 & 14721 & \\
\hline 41 & & & Piedras Negras & 151149 & 148195 & 98.0 & 51831 & 2211 & 4.3 & 2211 & 4.3 & 4.09 & -0.08 & 5.25 & 2.67 & 2.78 & 4882 & 32298 \\
\hline 1 & 5025 & 1 & Piedras Negras & 128130 & 126886 & 98.6 & 44451 & 1080 & 2.4 & 1181 & 2.6 & 4.39 & -0.87 & 5.98 & 2.08 & 2.72 & 4698 & 36669 \\
\hline 2 & 5022 & 2 & Nava & 23019 & 21809 & 94.7 & 7380 & 1131 & 15.8 & 1080 & 14.8 & 1.74 & 2.72 & 4.18 & 7.06 & 3.15 & 183 & 7966 \\
\hline 42 & & & Tulancingo & 148528 & 118634 & 79.9 & 55019 & 3229 & 5.9 & 3229 & 6.5 & 3.47 & 2.60 & 4.15 & 2.94 & 3.01 & 2518 & 16950 \\
\hline 1 & 19077 & 1 & Tulancingo de Bravo & 122274 & 101127 & 82.7 & 45207 & 328 & 0.7 & 2906 & 6.7 & 3.71 & 2.53 & 4.10 & 2.78 & 2.84 & 2289 & 18315 \\
\hline 2 & 13056 & 2 & Santiago Tulanteper de L Guersero & 26254 & 17507 & 66.7 & 9812 & 2906 & 29.6 & 823 & 5.3 & 2.18 & 3.00 & 4.42 & 3.77 & 3.85 & 278 & 10594 \\
\hline 43 & & & Apizaco & 137134 & 117197 & 85.5 & 46330 & 6834 & 14.8 & 6834 & 17.2 & 1.39 & 1.95 & 3.22 & 3.60 & 2.84 & 7218 & 52634 \\
\hline 1 & 29005 & 1 & Apizaco & 67675 & 62131 & 91.8 & 28915 & 1211 & 5.1 & 4511 & 19.2 & 2.04 & 2.63 & 8.34 & 8.24 & 2.74 & 2282 & 83716 \\
\hline 2 & 29031 & 2 & Tella de la Solidaridad & 21753 & 18857 & 86.7 & 7179 & 1359 & 18.9 & 1691 & 23.5 & 1.65 & 0.47 & 1.88 & 6.30 & 3.52 & 2594 & 119225 \\
\hline 3 & 29038 & 2 & Tzompantepec & 9294 & 5733 & 61.7 & 2921 & 1150 & 39.4 & 10 & 0.8 & 1.85 & 0.98 & 3.09 & 2.26 & -1.18 & 863 & 92872 \\
\hline 4 & 29039 & 2 & Xalozloc & 16857 & 16098 & 95.5 & 5220 & 1026 & 19.7 & 218 & 6.0 & -0.37 & 2.32 & 4.04 & 3.19 & 2,26 & 635 & 37653 \\
\hline 5 & 29043 & 2 & Yauhquemecan & 21555 & 14378 & 66.7 & 7095 & 2088 & 29.4 & 404 & 9.7 & 0.61 & 1.50 & 3.33 & 3.87 & 5.40 & 845 & 39198 \\
\hline 44 & & & Tainutlan & 133153 & 77055 & 57.9 & 47889 & 4133 & 8.6 & 4133 & 8.9 & 1.72 & 2.93 & 1.94 & 3.10 & 2.92 & 2243 & 16846 \\
\hline 1 & 21174 & 1 & Teziudán & 81156 & 62186 & 76.6 & 30681 & 123 & 0.4 & 3970 & 11.8 & 2.08 & 2.95 & 2.11 & 2.32 & 2.54 & 2147 & 26454 \\
\hline 2 & 21054 & 2 & Chignauta & 21571 & 8511 & 39.5 & 7499 & 1680 & 22.4 & 41 & 0.7 & 0.83 & 3.02 & -2.09 & 7.00 & 5.20 & 49 & 2295 \\
\hline
\end{tabular}




\section{CUADRO 1A (conclusión)}

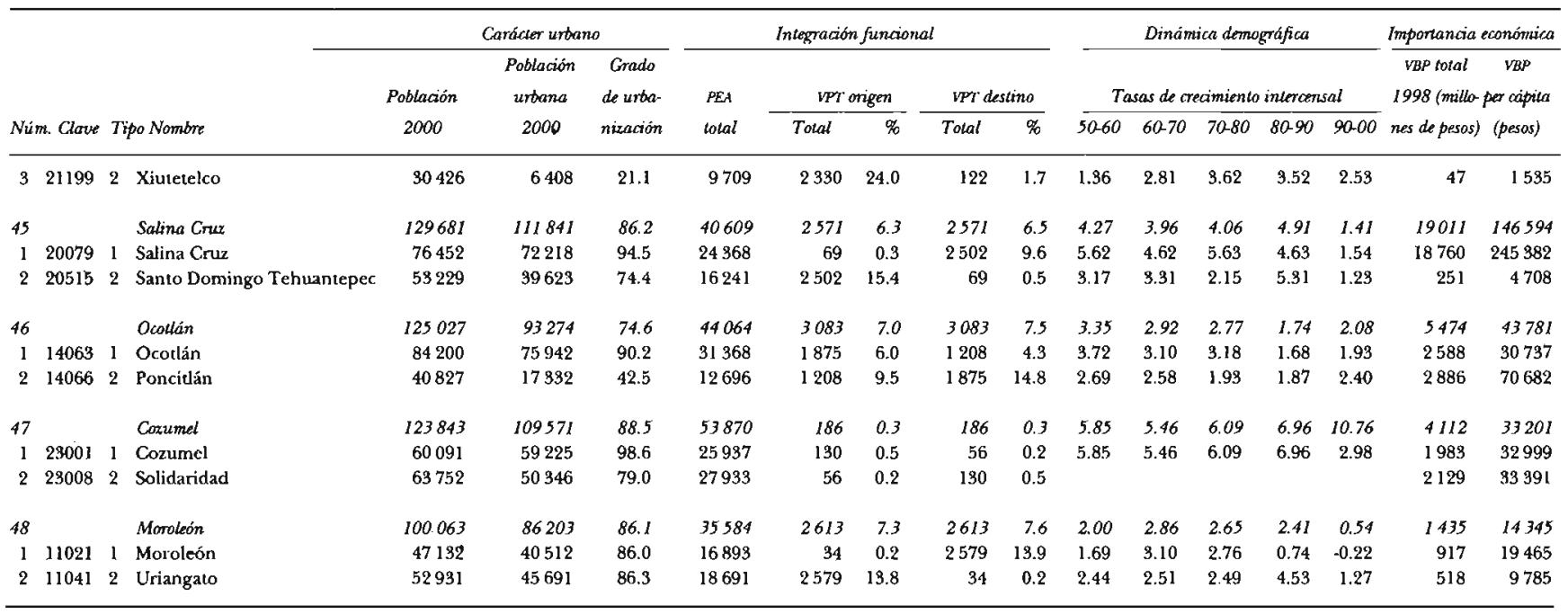

Fuente: Cálculos elaborados con información de Cunapo (1994), La población de los municipios de México, 1950-1990, Mëxico; iNEGI (2000), XV Censo industrial, XII Cemso comercial y XII Cen-

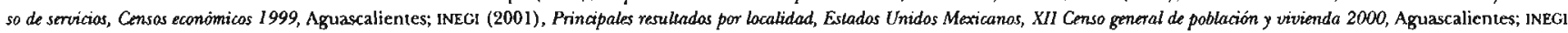
(2002), Información estadística, Sistema de consulua, Base de datos de la muestra censal (cuestionario ampliado), Aguascalientes (página web). 


\section{Bibliografía}

Alegría, T. (1992), Desarrollo urbano en la frontera México-Estados Unidos, Méxi$\mathrm{co}$, Consejo Nacional para la Cultura y las Artes.

Arias, R. (1990), La delimitación de una megalópolis. El desplazamiento diario de los trabajadores en el área de influencia inmediata de la Zona Metropolitana de la Ciudad de México, Zinacantepec, El Colegio Mexiquense.

Berry, B. y H. Kim (1993), "Challenges to the Monocentric Model", Geographical Analysis, vol. 25, núm. 1, pp. 1-4.

Brown, L y F. Stetzer (1984), "Development Aspects of Migration in Third World Settings: A Simulation, with Implications for Urbanisation", Environment and Planning, vol. 16, núm. 8, pp. 1583-1603.

Busquets, J. (1993), "Perspectiva desde las ciudades", Ciudad y Territorio. Estudios Territoriales, núm. 95-96, pp. 163-174.

Congreso de la Unión (1976), Ley General de Asentamientos Humanos, México, XIIX Legislatura.

Consejo Nacional de Población (1994), Evolución de las ciudades de México, 1900-1990, México, Secretaría de Gobernación.

Coombes, M., R. Dalla Longa y S. Raybould (1989), "Counterurbanisation in Britain and Italy", Progress in Planning, vol. 32, parte 1.

Cruz, M. S. (2002), "Procesos urbanos y 'ruralidad' en la periferia de la Zona Metropolitana de la Ciudad de México", Estudios Demográficos y Urbanos, vol. 17, núm. 1 (49), pp. 39-76.

Delgado, J., C. Anzaldo y A. Larralde (1999), "México City: Towards the Formation of a City-Region", en Guillermo Aguilar e Irma Escamilla (eds.), Problems of Megacities: Social Inequalities, Enviromental Risk and Urban Governance, México, Universidad Nacional Autónoma de México, pp. 599-611.

Ehrlich, S. y J. Gyourko (2000), "Changes in the Scale and Size Distribution of US Metropolitan Areas during the Twentieth Century", Urban Studies, vol. 37, núm. 7, pp. 1063-1077.

Erickson, R. (1983), "The Evolution of the Suburban Space Economy", Urban Geography, vol. 4, núm. 1, pp. 95-121.

Fielding, A. (1989), "Migration and Urbanisation in Western Europe since 1950", The Geographical Joumal, vol. 16, núm. 1, pp. 60-69.

Fujita, M., P. Krugman y A. Venables (2000), The Spatial Economy, Cambridge, Massachusetts, The MrT Press.

Garza, G. (1995), "Monterrey: ubicación en el sistema urbano nacional y expansión metropolitana", en G. Garza (coord.), Atlas de Monterrey, México, Gobierno del Estado de Nuevo León/Universidad Autónoma de Nuevo León/Instituto de Estudios Urbanos de Nuevo León/El Colegio de México, pp. 175-182.

General Register Office (1961), "The Growth and Study of Conurbations", en Jack Gibbs (ed.), Urban Research Methods, Nueva York, D. Van Nostrand Company, Inc., pp. 47-53. 
Geyer, H. y T. Kontuly (1993), "A Theoretical Foundation for the Concept of Differential Urbanization", International Regional Science Review, vol. 15, nüm. 12, pp. 157-177.

Gilbert, A. (1993), "Third World Cities: The Changing National Settlement System", Urban Studies, vol. 30, num. 45, pp. 721-740.

Gobierno del Distrito Federal, Secretaría de Desarrollo Social y Gobierno del Estado de México (1998), Programa de Ordenación de la Zona Metropolitana del Valle de México, México.

Goodall, Brian (1987), Dictionary of Human Geography, Londres, Penguin Books.

Hamburg, J. y R. Sharkey (1961), Land Use Forecast, Chicago, Chicago Area Transportation Studies.

INEGI (2002), Información estadística. Sistema de consulta. Base de datos de la muestra censal (cuestionario ampliado), Aguascalientes (página web).

- (1991), Área Metropolitana de la Ciudad de México. XI Censo general de población y vivienda 1990, Aguascalientes.

Johnson, J. (1977), Urban Geography, Oxford, Inglaterra, Pergamon Press.

Kasinitz, P. (ed.) (1995), Centre and Symbol of Our Times, Basingstoke, Inglaterra, MacMillan.

Korcelli, P. (1984), "The Turnaround of Urbanization in Developed Countries", en United Nations (ed.), Population Distribution, Migration and Development, Nueva York, pp. 349-372.

Massey, D. y M. Cordey-Hayes (1971), "The Use of Models in Structure Planning", Toum Planning Review, vol. 42, núm. 1, pp. 28-44.

Negrete, M. E. (2000), "Dinámica demográfica", en Gustavo Garza (coord.), La Ciudad de México en el fin del segundo milenio, México, El Colegio de México/Gobierno del Distrito Federal, pp. 247-255.

y H. Salazar (1986), "Zonas metropolitanas en México, 1980", Estudios Demográficos y Urbanos, vol. 1, núm. 1, pp. 97-124.

Pacione, M. (2001), Urban Greography, Londres, Routledge.

Poder Ejecutivo federal (2001), Programa Nacional de Desarrollo Urbano y Ordenación del Territorio, 2001-2006, México.

(1996), Programa Nacional de Desarrollo Urbano, 1995-2000, México.

Preston, S. (1988), "Urban Growth in Developing Countries: A Demographic Reappraisal", en J. Hugler (ed.), The Urbanization of the Third World, Oxford, Oxford University Press.

Rain, D. (1999), "Commuting Directionality. A Functional Measure for Metropolitan and Nonmetropolitan Area Standard", Urban Geography, vol. 20, núm. 8, pp. 749-767.

Rubalcava, R. M. y M. Schteingart (1985), "Diferenciación socioespacial intraurbana en el Área Metropolitana de la Ciudad de México", Estudios Sociológicos, vol. 3, núm. 9, pp. 481-514.

Secretaría de Asentamientos Humanos y Obras Públicas (1978), El fenómeno de conurbación en el sistema jurídico mexicano, México. 
Stuart, F. (1965), "A Model for Simulating Residential Development", Joumal of the American Institute of Planners, vol. 31, núm. 1, pp. 120-125.

Suarez-Villa, L. (1988), "Metropolitan Evolution, Sectorial Economic Change, and the City Size Distribution", Urban Studies, vol. 25, núm. 1, pp. 120.

Unikel, L., C. Ruiz y G. Garza (1978), El desarrollo urbano de México, México, El Colegio de México.

United Nations (1999), World Population Prospects: The 1999 Revision, Nueva York.

U.S. Bureau of the Census (1959), "Census Areas of 1950", en Mayer Harold, y Clyde Kohn (eds.), Readings in Urban Geography, Chicago, The University of Chicago Press, pp. 29-32.

Van der Laan, L. (1998), "Changing Urban Systems: An Empirical Analysis at Two Spatial Levels", Regional Studies, vol. 23, núm. 3, pp. 235-247.

Vining, D. y T. Kontuly (1978), "Population Dispersal from Major Metropolitan Regions: An International Comparison", International Regional Science Review, vol. 3, núm. 1, pp. 4973.

Weber, A. (1967), The Growth of Cities in the Nineteenth Century, Ithaca, Nueva York, Cornell University Press.

Ziccardi, A. (2000), Municipio y región, México, Instituto de Investigaciones Sociales de la UnAM, Agenda de la Reforma Municipal de México (Cuadernos de Debate). 